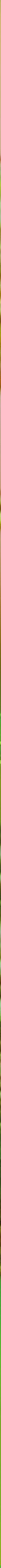

\title{
Herkomstenonderzoek van gewone esdoorn (Acer pseudoplatanus) in Nederland
}





\section{Herkomstenonderzoek van gewone esdoorn (Acer pseudoplatanus) in Nederland}

Inge Verbeek, Paul Copini, Ute Sass-Klaassen, Annelinde Dingemanse \& Joukje Buiteveld

Dit onderzoek is uitgevoerd door CGN, in opdracht van en gefinancierd door de Raad voor plantenrassen, in het kader van het Cultuur- en Gebruikswaarde Onderzoek (CGO) t.b.v. de Rassenlijst Bomen, maar geschiedt onder verantwoordelijkheid van de auteur(s) en vertegenwoordigt niet noodzakelijkerwijs de mening van de Raad.

Centre for Genetic Resources, the Netherlands (CGN), Wageningen University \& Research Wageningen, juli 2021 
Verbeek, I., P. Copini, U. Sass-Klaassen, A. Dingemanse \& J. Buiteveld, 2021. Herkomstenonderzoek van gewone esdoorn (Acer pseudoplatanus) in Nederland. Centre for Genetic Resources, the Netherlands (CGN), Wageningen University \& Research, CGN rapport 52. 36 blz.; 8 fig.; 5 tab.; 35 ref.

Dit rapport geeft de resultaten van een herkomstentoets van de gewone esdoorn (Acer pseudoplatanus). In totaal zijn negentien herkomsten afkomstig uit Nederland, Duitsland en België vergeleken voor de eigenschappen overleving, bladuitloop, diameter en hoogtegroei, stamrechtheid en vorken. De proef werd uitgevoerd op één proefveldlocatie in de provincie Flevoland (Nederland). Op basis van de resultaten worden er aanbevelingen gedaan voor het gebruik van de buitenlandse herkomsten voor aanplant in Nederland.

This report presents the evaluation of growth of 19 provenances of sycamore (Acer pseudoplatanus). The provenances originate from the Netherlands, Germany and Belgium. Tested characteristics were: survival, leaf flushing, growth (diameter, height), stem straightness and forking. The research was conducted at one trial site in the Horsterwold in the province of Flevoland, the Netherlands. Based on the results, recommendations are made for using these provenances in the Netherlands.

Dit rapport is gratis te downloaden op http://doi.org/10.18174/551151 of op www.wur.nl/cgn onder CGN rapporten.

(C) 2021 Centre for Genetic Resources, the Netherlands (CGN), Wageningen University \& Research E cgn@wur.nl

Wageningen University \& Research aanvaardt geen aansprakelijkheid voor eventuele schade voortvloeiend uit het gebruik van de resultaten van dit onderzoek of de toepassing van de adviezen.

Alle rechten voorbehouden. Niets uit deze uitgave mag worden vermenigvuldigd en/of openbaar gemaakt worden door middel van druk, fotokopie, microfilm of op welke wijze dan ook zonder voorafgaande toestemming van de uitgever of auteur.

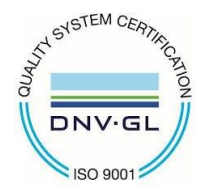

De certificering volgens ISO 9001 onderstreept ons kwaliteitsniveau. 


\section{Inhoud}

Woord vooraf $\quad 5$

$\begin{array}{ll}\text { Samenvatting } & 7\end{array}$

1

$\begin{array}{lr}\text { Inleiding } & 9\end{array}$

2

Materiaal \& Methode $\quad 12$

2.1 Materiaal 12

2.2 Proefopzet 13

2.3 Waarnemingen $\quad 14$

2.4 Jaarringonderzoek 14

$\begin{array}{lll}2.5 & \text { Data-analyse } & 15\end{array}$

$\begin{array}{llr}3 & \text { Resultaten } & 16\end{array}$

3.1 Overleving 16

$\begin{array}{lll}3.2 & \text { Bladuitloop } & 17\end{array}$

$\begin{array}{lll}3.3 \text { Groei } & 17\end{array}$

$\begin{array}{lll}3.4 & \text { Vorm } & 19\end{array}$

$\begin{array}{ll}3.5 & \text { Jaarringonderzoek }\end{array}$

4.1 Kwaliteit en aangepastheid van de herkomsten $\quad 23$

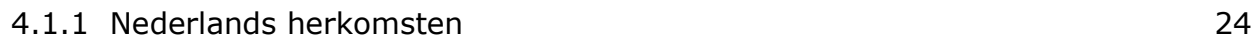

4.1.2 Duitse herkomsten $\quad 24$

4.1.3 Belgische herkomsten $\quad 25$

4.2 Effect van de 2018 droogte op groei van gewone esdoorn 25

4.3 Aanbevelingen Rassenlijst Bomen $\quad 26$

4.3.1 Nederlandse herkomsten $\quad 26$

4.3.2 Duitse herkomsten $\quad 26$

$\begin{array}{ll}\text { 4.3.3 Belgische herkomsten } & 26\end{array}$

$\begin{array}{ll}\text { Literatuur } & \mathbf{2 7}\end{array}$

$\begin{array}{lll}\text { Bijlage } 1 \text { Achtergrondgegevens herkomsten } & 29\end{array}$

Bijlage 2 Herkomstgebieden Duitsland en België 30

Bijlage 3 INS-CGN-FG-079 Protocol uitloopstadia Acer soorten 31

Bijlage 4 Protocol rechtheid $\quad 32$

$\begin{array}{lll}\text { Bijlage } 5 & \text { Protocol vorken } & 33\end{array}$

Bijlage $6 \quad$ Bladuitloop 2011 \& 2012

Bijlage 7 Diameter en Hoogte 20 beste bomen per herkomst 35 



\section{Woord vooraf}

In dit rapport worden de resultaten van een herkomstenproef van gewone esdoorn (Acer pseudoplatanus) gepresenteerd. Het onderzoek maakt deel uit van het Cultuur- en Gebruikswaarde Onderzoek (CGO) ten behoeve van de Rassenlijst Bomen en wordt uitgevoerd door het Centrum voor Genetische Bronnen Nederland (CGN), in opdracht van de Raad voor plantenrassen (Rvp). Het jaarringonderzoek werd mogelijk gemaakt vanuit de klimaatenveloppe "Vergroten kennis en beschikbaarheid 'klimaat-slimme' boomsoorten en herkomsten".

Aan het onderzoek werkten diverse medewerkers van het Staatsbosbeheer (SBB) en Wageningen University \& Research mee. Graag willen we de beheerseenheid 'Horsterwold' van Staatsbosbeheer en in het bijzonder Jan van Veen en Vincent Troost bedanken voor het beschikbaar stellen van het terrein voor de proef en de hulp bij aanleg en beheer van het proefveld. Verder danken we de medewerkers van Wageningen University \& Research Triye Huibers, Wim van Orden, Geurt van Roekel, Toon Helmink en Otto Vaessen voor het uitvoeren van de metingen en waarnemingen, en de Silve-medewerkers Marcel Lusink en Arno van der Sluis voor hulp bij de laatste metingen. Als laatste bedanken we Paul Goedhart voor de statistische ondersteuning. 


\section{Samenvatting}

Sinds 1 januari 2003 ressorteert de gewone esdoorn (Acer pseudoplatanus) onder EU Richtlijn 1999/105/EG betreffende het in de handel brengen van bosbouwkundig teeltmateriaal. Dit betekent dat van deze soort uitsluitend teeltmateriaal van een voldoende genetische kwaliteit en gecertificeerd conform EU-normen in de handel gebracht mag worden. Momenteel is er één zaadopstand in de categorie 'geselecteerd uitgangsmateriaal' (S) en zijn er drie zaadgaarden in de categorie 'gekeurd uitgangsmateriaal (ZQ) toegelaten in de rassenlijst bomen.

In 2004 is er een herkomstentoets aangelegd waarin vijf Nederlandse herkomsten worden vergeleken met vijf Belgische en negen Duitse herkomsten met als doel inzicht te krijgen in de aangepastheid, productiviteit en kwaliteit van dit Nederlandse en buitenlandse uitgangsmateriaal van de gewone esdoorn. Buitenlandse herkomsten die in Nederlandse proeven een combinatie van goede eigenschappen laten zien (goede groei, hoge overleving, laat uitlopen en goede vorm), hebben de grootste kans het als aanplantingen goed te doen onder Nederlandse omstandigheden. Deze herkomsten kunnen worden aanbevolen via de Rassenlijst Bomen, als deze zijn toegelaten tot de Nationale Rassenlijsten van de betreffende landen. De herkomsten in dit vergelijkend onderzoek zijn beoordeeld op overleving, bladuitloop, hoogte- en diametergroei en vormkenmerken. De herkomsten laten verschillen zien voor alle eigenschappen. Op grond van de resultaten uit deze herkomstenproef concluderen we dat als aanvulling op de Nederlandse herkomsten, de Duitse herkomsten Kattenbühl (186), Mertener Heide (187), Roddergrube (188), Fa. Mettmann (189) en Grohnde (194) en de Belgische herkomsten Tachètes (197), Grandes Hayes (198) en Mont-Yvoir (199) kunnen worden aanbevolen voor aanplant in Nederland. 


\section{$1 \quad$ Inleiding}

De gewone esdoorn (Acer pseudoplatanus) is een loofboomsoort die van nature in continentaal Europa en Klein Azië voorkomt (Figuur 1). Zo wordt de soort in veel Europese landen als inheems beschouwd, met uitzondering van Ierland, het Verenigd Koninkrijk en de noordelijkste delen van Europa (Peterken, 2001). In Nederland komt de soort van nature vermoedelijk voor in Zuid-Limburg, elders is deze geïntroduceerd en verwilderd (Figuur 1). De status als inheemse boomsoort heeft in onze contreien, maar ook in Engeland en België vaak ter discussie gestaan (Peterken, 2001; De Keersmaeker et al., 2016). Het areaal gewone esdoorn in Nederland is laag, met een geschatte grootte van 3851 ha (1\%) (Schelhaas et al., 2014). Vanwege zowel ecologische als productieaspecten is er tegenwoordig meer interesse in deze boomsoort (Hein et al., 2009; De Keersmaeker et al., 2016). Ook wordt de soort gezien als een alternatief voor productiebossen waar de es is uitgevallen door de essentaksterfte (Mitchell et al., 2014).

Op Europese schaal worden delen van Nederland getypeerd als (zeer) geschikt voor gewone esdoorn (Pasta et al., 2016). De gewone esdoorn kan goed gedijen op de meeste bodems, zolang deze een goed vochtleverend vermogen hebben (Rusanen and Myking, 2003; Pasta et al., 2016). De soort kan zich gemakkelijk verspreiden via de gevleugelde zaden. Onder meer in duingebieden wordt de talrijke verjonging soms als problematisch beschouwd (Olsthoorn et al., 2001). Ook in andere groeiplaatsen moet rekening worden gehouden met het potentieel invasieve karakter van de boomsoort, die in relatief korte tijd dominant kan worden ook in omliggende opstanden (Hein et al., 2009). Als juveniel kan de gewone esdoorn zich goed ontwikkelen in de schaduw, al heeft de soort op latere leeftijd wel meer licht nodig (halfschaduwsoort). Als juveniele boom is de soort ook kwetsbaarder voor late vorst in het voorjaar (Daws and Pritchard, 2008; Pasta et al., 2016). Mogelijk heeft de gewone esdoorn profijt van temperatuurstijging als gevolg van klimaatverandering (Hanewinkel et al., 2013). Wel wordt toenemende zomerdroogte of ziekten en plagen gezien als een risico voor de gewone esdoorn (Pasta et al., 2016; Morecroft et al., 2008). Een van de opkomende ziekten in gewone esdoorn is roetschors, veroorzaakt door de schimmel Cryptostroma corticale; deze boomziekte kan ook schadelijk zijn voor de mens (Roskams, 2021).

Gewone esdoorn heeft een redelijk goede strooiselkwaliteit; het strooisel breekt langzamer af dan bij populier of es, maar aanzienlijk sneller dan bij beuk en eik (De Keersmaeker et al., 2016; Desie et al., 2020). Dankzij deze eigenschap heeft de gewone esdoorn een gunstige werking op de strooiselkwaliteit in zure eiken- of beukenbossen, waar verzuringsgevoelige bosflora baat bij heeft (De Keersmaeker et al., 2016). In Nederland wordt vanwege deze gunstige eigenschap ook geëxperimenteerd met de aanplant op armere gronden, o.a. in Grove dennenbossen (Lindenbergh, 2020; Thomassen, 2020). Net zoals de zoete kers en de linde is de gewone esdoorn een belangrijke nectarbron in het voorjaar voor o.a. de honingbij. De basische schors kan, vooral in vochtige gebieden, een diverse epifytengemeenschap bevatten (Binggeli, 1993).

De gewone esdoorn kent een snelle jeugdgroei die vaak 20 à 25 jaar aanhoudt, waarna de groei afvlakt. Op geschikte gronden is het één van de productiefste loofboomsoorten (Pasta et al., 2016). In Wallonië kan de hoogtegroei maar liefst 19,5 m bedragen op 20-jarige leeftijd (Claessens et al., 1999). In Nederland groeit de gewone esdoorn op goede grond tot ca. $16 \mathrm{~m}$ in hoogte na 20 jaar (Jansen et al., 2018). De soort heeft een goede natuurlijke takafstoting (Hein et al., 2008). Het hout heeft een gelijkmatige structuur, is sterk en hard, licht van kleur en geurloos. Het hout is niet bijzonder duurzaam, dus toepassingen liggen vooral in meubels, muziekinstrumenten of fineer en hier kunnen relatief hoge prijzen voor gevraagd worden (Rusanen and Myking, 2003; Carón et al., 2015). Daarnaast wordt het hout in sommige landen gebruikt als zaaghout (Hein et al., 2009). Ook is het hout van de gewone esdoorn geschikt voor chemische of thermische modificatie, waardoor het voor hoogwaardige toepassingen gebruikt kan worden (Klaassen et al., 2021; Kupers et al., 2020). 


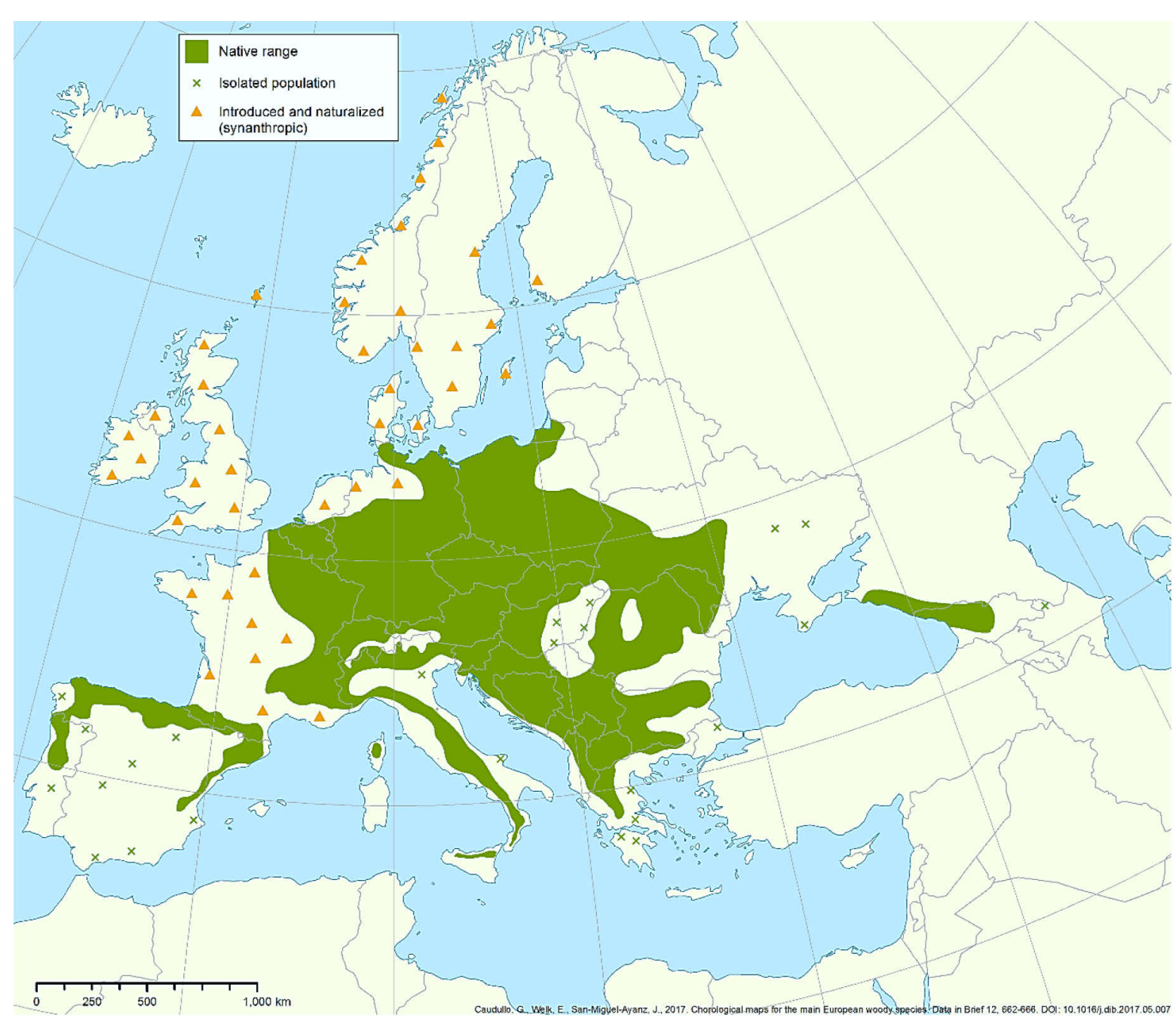

Figur 1 Verspreidingskaart van Acer pseudoplatanus (Caudullo et al., 2017).

De zaadvoorziening uit Nederlandse opstanden is beperkt, omdat van gewone esdoorn relatief weinig kwalitatief goede opstanden bekend zijn. Momenteel is er één zaadopstand (Geldermalsen-01, categorie 'geselecteerd') en zijn er drie zaadgaarden (categorie 'gekeurd') toegelaten tot de Rassenlijst Bomen (www.rassenlijstbomen.nl). Er zijn geen autochtone herkomsten beschikbaar. In de jaren tachtig en begin negentig van de vorige eeuw zijn de zaadgaarden (Vaartbos-01, Vaartbos-02, Zeewolde-01 en Zetten-01) aangelegd om het tekort aan goede zaadopstanden te compenseren. Bij de aanleg van bossen en beplantingen werd in het verleden nogal eens gebruikgemaakt van plantsoen waarvan de herkomst onbekend is. Dit was in het verleden mogelijk, echter sinds 1 januari 2003 ressorteert gewone esdoorn onder de EU Richtlijn 1999/105/EG betreffende het in de handel brengen van bosbouwkundig teeltmateriaal. Dit betekent dat van deze soort uitsluitend teeltmateriaal van een voldoende genetische kwaliteit conform EU-normen gecertificeerd in de handel gebracht mag worden.

Het Centrum voor Genetische Bronnen Nederland (CGN) voert onderzoek uit naar de genetische kwaliteit van het uitgangsmateriaal van gewone esdoorn voor aanplant in Nederland. Het onderzoek was in het verleden voornamelijk gericht op het selecteren van klonen van gewone esdoorn, belangrijk voor de aanplant in het stedelijk gebied. Vanaf de jaren tachtig zijn ook nakomelingschapstoetsen aangelegd van geselecteerde plusbomen voor het opzetten van zaadgaarden. Daarnaast kunnen herkomstenproeven worden gebruikt om zaadbronnen te identificeren, die aangepast plantmateriaal met een hoge productiecapaciteit voor bosbouwkundig gebruik kunnen leveren. Deze kennis van de kwaliteit van de voor zaadwinning geselecteerde herkomsten is nodig om slecht geslaagde aanplantingen en tegenvallende resultaten met betrekking tot de kwaliteit van het teeltmateriaal zo veel mogelijk te voorkomen. 
Geregistreerde herkomsten in het buitenland (European Commission, 2015) zijn mogelijk geschikt voor teelt in Nederland. Voorwaarde is echter dat het materiaal van goede genetische kwaliteit is en optimaal aangepast aan de groeiomstandigheden in Nederland. Bij voorkeur worden resultaten uit herkomstentoetsen gebruikt om de geschiktste buitenlandse herkomsten te kunnen kiezen voor aanplant. Er is slechts beperkte kennis over herkomstverschillen voor morfologie, fenologie of groei bij esdoorn op basis van herkomstenproeven, zowel in Nederland als op Europees niveau (zie ook Krabel \& Wolf (2013) voor een overzicht). De weinige herkomstenproeven die er zijn, laten veelal een herkomsteffect zien voor groei, ook op kleine geografische schaal, maar zonder een duidelijk geografisch patroon. Cundall et al. (1998) vergeleken lokale herkomsten uit Groot-Brittannië met herkomsten uit Denemarken, Frankrijk en Duitsland, aangelegd op diverse locaties in Groot-Brittannië. Hun conclusie is dat de verschillen tussen herkomsten voor groei klein zijn. Beoordeling van de herkomsten op 27-jarige leeftijd bevestigde deze resultaten. Wel bleken er duidelijke verschillen te zijn in het tijdstip van bladuitloop; Franse en Duitse herkomsten liepen later uit ten opzichte van Britse herkomsten (Whittet et al., 2021).

In 2004 is een herkomstentoets van gewone esdoorn aangelegd in Nederland waarin Nederlandse herkomsten vergeleken worden met Belgische en Duitse herkomsten. De doelstellingen van dit herkomstenonderzoek waren:

- Inzicht krijgen in de kwaliteit en aangepastheid van buitenlandse herkomsten ten opzichte van Nederlandse herkomsten door middel van een vergelijkende toetsproef.

- Het doen van aanbevelingen over het gebruik van deze buitenlandse herkomsten voor aanplant in Nederland.

In dit rapport worden de eerste resultaten van deze herkomstenproef beschreven. Daarnaast is deze herkomstenproef gebruikt om inzicht te krijgen in het effect van het extreem droge jaar 2018 op de groei van de gewone esdoorn.

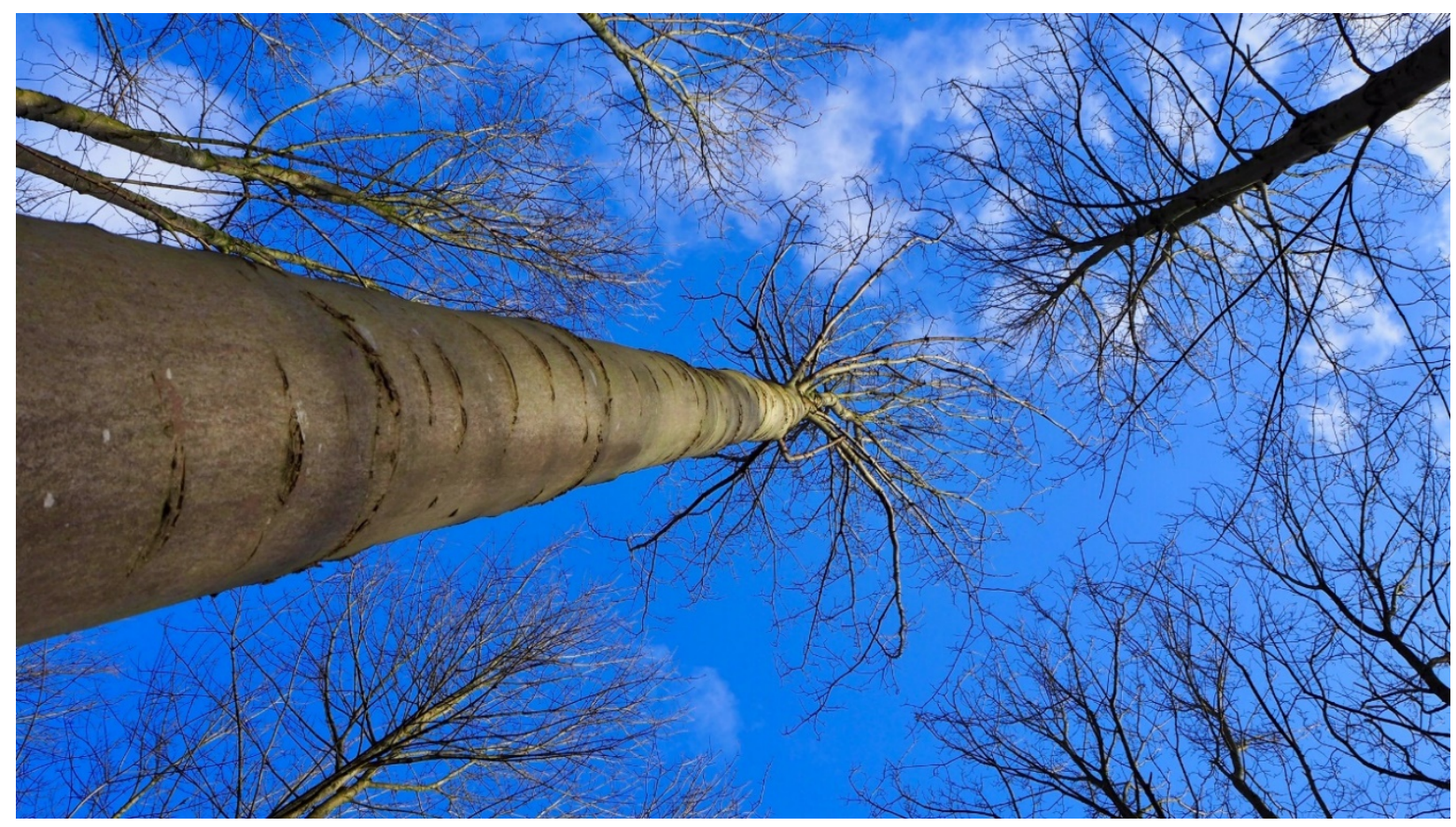

Figuur 2 40-jaar oude gewone esdoorn in het Horsterwold. 


\section{Materiaal \& Methode}

\section{$2.1 \quad$ Materiaal}

In deze proef zijn in totaal negentien herkomsten getoetst. Vijf herkomsten zijn uit Nederland afkomstig, negen uit Duitsland en de overige vijf uit België (Figuur 3). In 2002 is er zaad geoogst uit vier Nederlandse zaadgaarden en één Nederlandse opstand, alle toegelaten tot de rassenlijst bomen. Uit Duitsland en België werd op verzoek zaadmateriaal ontvangen. Alle zaden werden eind 2002 uitgezaaid bij een kwekerij in Agtmaal. Zie Tabel 1 en Bijlage 1 voor details van de herkomsten.

De Duitse herkomsten zijn afkomstig uit twee herkomstgebieden Westdeutsches Bergland, kolline stufe (801 03) en montane stufe 80104 (Bijlage 2). De Belgische herkomsten zijn afkomstig uit vier herkomstgebieden, namelijk 'Ten Noorden van Samber en Maas, Laag Maasplateau, Ardennen en Lotharingen'. Zie Bijlage 2 voor herkomstgebieden in België.

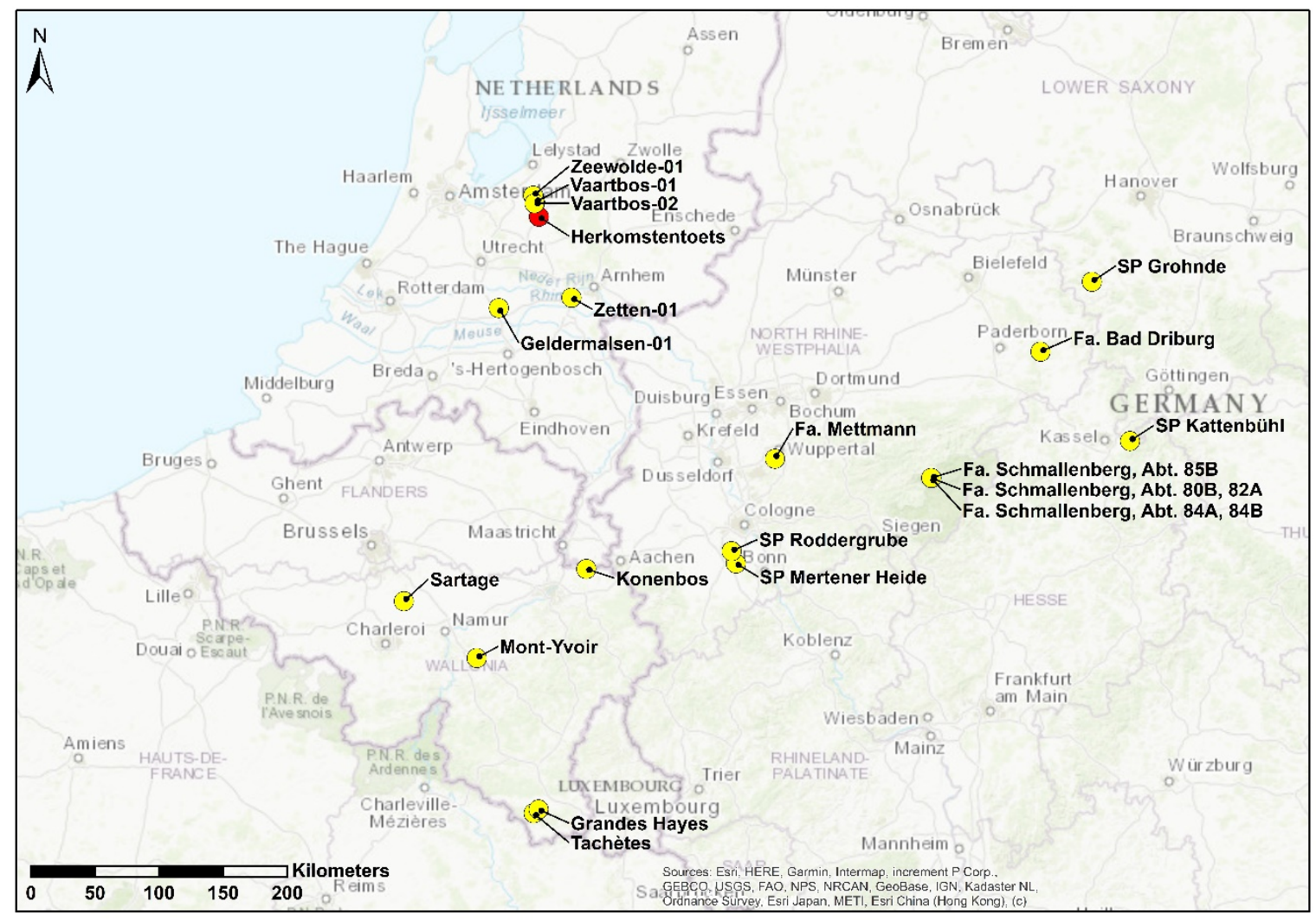

Figuur 3 Kaart van West-Europa met locaties van herkomsten (geel) en proefveld (rood). 
Tabel 1 Overzicht van herkomsten van esdoorn gebruikt in de proef. Voor achtergrondinformatie over de herkomsten zie Bijlage 1.

\begin{tabular}{|c|c|c|c|c|}
\hline Selnr. & Herkomstnaam & Type en categorie* & Land/Regio & Herkomstgebied \\
\hline 181 & Vaartbos-01 & Zaadgaard, gekeurd & Nederland & Nederland \\
\hline 182 & Vaartbos-02 ** & Zaadgaard, gekeurd & Nederland & Nederland \\
\hline 184 & Zetten-01 & Zaadgaard, gekeurd & Nederland & Nederland \\
\hline 185 & Geldermalsen-01 & Opstand, geselecteerd & Nederland & Nederland \\
\hline 187 & SP Mertener Heide & Zaadgaard, gekeurd & $\begin{array}{l}\text { Duitsland/ } \\
\text { Nordrhein-Westfalen }\end{array}$ & $\begin{array}{l}\text { Westdeutsches Bergland, kolline Stufe } \\
\text { (801 03) }\end{array}$ \\
\hline 188 & SP Roddergrube & Zaadgaard, gekeurd & $\begin{array}{l}\text { Duitsland/ } \\
\text { Nordrhein-Westfalen }\end{array}$ & $\begin{array}{l}\text { Westdeutsches Bergland, montane } \\
\text { Stufe (801 04) }\end{array}$ \\
\hline 190 & $\begin{array}{l}\text { Fa. Bad Driburg, Staatswald } \\
\text { Abt. } 174 \mathrm{~B}, 175 * * *\end{array}$ & Opstand, geselecteerd & $\begin{array}{l}\text { Duitsland/ } \\
\text { Nordrhein-Westfalen }\end{array}$ & $\begin{array}{l}\text { Westdeutsches Bergland, kolline Stufe } \\
\text { (801 03) }\end{array}$ \\
\hline 191 & $\begin{array}{l}\text { Fa. Schmallenberg, Staatswald } \\
\text { Abt. } 80 \mathrm{~B}, 82 \mathrm{~A} * * *\end{array}$ & Opstand, geselecteerd & $\begin{array}{l}\text { Duitsland/ } \\
\text { Nordrhein-Westfalen }\end{array}$ & $\begin{array}{l}\text { Westdeutsches Bergland, montane } \\
\text { Stufe (801 04) }\end{array}$ \\
\hline 192 & $\begin{array}{l}\text { Fa. Schmallenberg, Staatswald } \\
\text { Abt. 84A, 84B *** }\end{array}$ & Opstand, geselecteerd & $\begin{array}{l}\text { Duitsland/ } \\
\text { Nordrhein-Westfalen }\end{array}$ & $\begin{array}{l}\text { Westdeutsches Bergland, montane } \\
\text { Stufe (801 04) }\end{array}$ \\
\hline 193 & $\begin{array}{l}\text { Fa. Schmallenberg, Staatswald } \\
\text { Abt. } 85 \mathrm{~B} * * *\end{array}$ & Opstand, geselecteerd & $\begin{array}{l}\text { Duitsland/ } \\
\text { Nordrhein-Westfalen }\end{array}$ & $\begin{array}{l}\text { Westdeutsches Bergland, montane } \\
\text { Stufe ( } 801 \text { 04) }\end{array}$ \\
\hline 194 & SP Grohnde & Zaadgaard, gekeurd & $\begin{array}{l}\text { Duitsland/ } \\
\text { Niedersachsen }\end{array}$ & $\begin{array}{l}\text { Westdeutsches Bergland, kolline Stufe } \\
\text { (801 03) }\end{array}$ \\
\hline 198 & Grandes Hayes & Opstand, geselecteerd & België/Wallonië & $\begin{array}{l}\text { Ten Zuiden van Samber en Maas } \\
\text { (Lotharingen) }\end{array}$ \\
\hline 199 & Mont-Yvoir & Zaadgaard, gekeurd & België/Wallonië & $\begin{array}{l}\text { Ten Zuiden van Samber en Maas (Laag } \\
\text { Maasplateau) }\end{array}$ \\
\hline
\end{tabular}

\subsection{Proefopzet}

Het proefveld is aangelegd in december 2004 in het Horsterwold (Staatbosbeheer, vak 356-g2, coördinaten, $52.2852 \mathrm{~N}, 5.5198 \mathrm{E})$ met tweejarig (1+1) plantsoen. De proef is aangelegd op een kalkrijke poldervaaggrond (klei) met grondwatertrap VI. Voor de aanleg van dit proefveld was het perceel bebost met fijnspar (kiemjaar 1975). De proef is opgezet als een orthogonale gerandomiseerde blokkenproef met drie herhalingen. Per herhaling (blok) zijn 25 planten $(5 \times 5)$ per herkomst geplant in een plot met een plantverband van 1,5 bij $1 \mathrm{~m}$. Randomisatie is gedaan door loting binnen de drie blokken. Rondom het proefveld zijn twee rijen randbomen aangeplant. In december 2005 is één boom (selnr. 193) ingeboet. Tot aan 2020 zijn er geen (systematische) dunningen uitgevoerd. 


\subsection{Waarnemingen}

In Tabel 2 wordt vermeld op welk tijdstip overleving, bladuitloop en vorm is waargenomen en wanneer hoogte en diameter zijn gemeten. Overleving werd bepaald door bij elke opname van de hoogte, uitloopstadium of vorm het percentage levende bomen vast te stellen aan de hand van het aantal waarnemingen per plot. Bladuitloop werd in het voorjaar opgenomen volgens een protocol (INS-CGNFG-079 v1) met zes klassen: 1) knop in rust, 2) knop begint te zwellen, 3) knop net zichtbaar open, 4) bladeren beginnen met ontvouwen, 5) blad gedeeltelijk ontvouwd, 6) blad volledig ontwikkeld (Bijlage 3). De hoogte is gemeten met een telescoopstok (2010 \& 2015) of optische hoogtemeter (2020) en de diameter met pi-band (2015) of boomklem (2020). Rechtheid van de stam is beoordeeld volgens protocol T4F D2.1, 3.161 met vijf klassen: 1) struikgroei, 2) matig tot sterk gebogen stam, 3) licht tot matig gebogen stam in meerdere richtingen, 4) lichte kromming in één richting, 5) rechte stam (Bijlage 4). Vorken zijn beoordeeld volgens protocol T4F D2.1, 3.162 met vijf klassen:

1) meerdere vorken in bovenste en onderste deel van de boom, 2) lage vork alleen in onderste helft van de boom, 3) hoge vork alleen in bovenste helft van de boom, 4) zuiger, 5) geen vorken (Bijlage 5).

Tabel 2 Overzicht van uitgevoerde warnemingen en metingen in de proef.

\begin{tabular}{lll} 
Eigenschap & Tijdstip & Methode/eenheid \\
Overleving & $2010,2011,2012,2015,2020$ & \% levende bomen \\
\hline Bladuitloop & $2010,2011,2012$ & in klasses $(1-6)$ \\
\hline Hoogte & $2010,2015,2020$ & in meters \\
\hline Diameter & 2015,2020 & DBH (in cm) \\
\hline Vorken & 2020 & in klassen $(1-5)$ \\
\hline Stamvorm & 2020 & in klassen $(1-5)$
\end{tabular}

\subsection{Jaarringonderzoek}

Om inzicht te krijgen in het effect van het extreem droge jaar 2018 op de groei van de gewone esdoorn, zijn drie herkomsten (selnrs. 181, 193 \& 198) geselecteerd voor jaarringonderzoek. Deze herkomsten zijn geselecterd op productiviteit, variërend van ondergemiddeld (sel 193), gemiddeld (selnr. 181) en bovengemiddeld (selnr. 198). Per herkomst zijn van tien dominante bomen, verdeeld over alle herhalingen in het proefveld, houtmonsters verzameld met een aanwasboor (diameter $5 \mathrm{~mm}$ ). De houtmonsters zijn op $50 \mathrm{~cm}$ stamhoogte genomen in maart 2020. Op het DendroLab van Wageningen Universiteit zijn de boorkeren in houten houders geplakt om kromtrekken tijdens het drogen te voorkomen. Vervolgens werd de kopse kant van de boorkernen met een microtoom oversneden om de jaarringen duidelijk zichtbaar te maken. De jaarringbreedtes werden onder een binoculair (vergroting 10-40 maal) op een dendrochronologische meettafel (LINTAB, Rinntec) met een nauwkeurigheid van 1/100 mm opgemeten. De meetgegevens werden met behulp van het meet- en analyseprogramma WinTSAP bewerkt. De jaarringreeksen zijn per herkomst visueel en statistisch onderling vergeleken (kruisdateren) om voor mogelijke meetfouten te corrigeren en elke jaarringbreedte exact te koppelen aan een kalenderjaar. Vervolgens zijn chronologieën (= middelcurves) per herkomst berekend. Om het effect van de extreme droogte van 2018 op de groei te beoordelen, zijn drie indexen berekend (Lloret et al., 2011). De index resistance beschrijft de groeiverandering van de boom tijdens de droogte (2018) ten opzichte van de jaren voor de droogte (2015-2017). De index recovery beschrijft de groeiverandering na de droogte (2019) ten opzichte van het droogtejaar 2018 en de index resilience beschrijft de groei van na de droogte (2019) ten opzichte van de periode voor de droogte (2015-2017). Daarnaast is op basis van de diameter op monsterhoogte de cumulatieve oppervlakte van de stamdoorsnede berekend om het effect van de extreme droogte van 2018 op groei te beoordelen. 


\subsection{Data-analyse}

Alle analyses zijn uitgevoerd in R (versie i386 3.6.1) m.b.v. RStudio (Version1.0.153). Er is gebruikgemaakt van de volgende R-packages: 'ordinal' (2019.12-10), 'emmeans' (1.3.5.1), 'multcomp' (1.4-10), 'multcomView' (0.1-8), 'Ime4' (1.1-21) en 'pbkrtest' (0.4-7). Binaire overlevingsdata zijn statistisch geanalyseerd met een logistisch regressiemodel. Ordinale data bladuitloop en stamkenmerken zijn geanalyseerd met een zogenaamd drempelmodel (ordinal logistic regression model). Hier wordt een multinomiale verdeling verondersteld. De continue hoogte- en diameterdata zijn geanalyseerd met een lineair mixed effect model. Voor alle analyses wordt de plot, met 25 bomen per herkomst, als experimentele eenheid genomen. Waar nodig wordt gecompenseerd voor overdispersie. Paarsgewijze vergelijkingen tussen herkomsten zijn uitgevoerd met een multiple comparison Tukey toets met een onbetrouwbaarheidsdrempel van 5\%. Daarnaast zijn er contrasten uitgerekend m.b.v. least-square means om te beoordelen welke herkomsten significant afwijken ten opzichte van het gemiddelde over alle herkomsten. Deze toetsen zijn niet gecorrigeerd voor meerdere vergelijkingen; in plaats daarvan is een onbetrouwbaarheidsdrempel van $1 \%$ aangehouden. Waarden met $5 \%$ onbetrouwbaarheidsdrempel worden ook getoond. 


\section{Resultaten}

\subsection{Overleving}

De bomen in het proefveld zijn zeer goed aangeslagen. In het eerste jaar is slechts één enkele boom ingeboet. Het gemiddelde overlevingspercentage op 8-jarige leeftijd van de gehele proef (in 2010) was $98 \%$. Tot en met 2015 was er geen significant verschil tussen herkomsten. In 2020, op 18-jarige leeftijd, zijn er significante verschillen in overleving tussen de herkomsten $(p<0,001)$. De overleving in 2020 varieert van 37\% (Fa. Schmallenberg, selnr. 191) tot 83\% (zaadgaard Zeewolde-01, selnr. 183). De herkomsten met de hoogste overleving zijn de zaadgaarden Vaartbos-02 (selnr. 182), Zeewolde-01 (selnr. 183), Mont-Yvoir (selnr. 199) en Grandes Hayes (selnr. 198). De drie Duitse herkomsten uit Fa. Schmallenberg (selnrs. 191, 192 en 193) en de herkomst Konenbos (selnr. 195) hebben de laagste overleving en wijken significant af van het proefveldgemiddelde (Tabel 3). Twee Duitse opstanden uit Fa. Schmallenberg (selnrs. 191 en 192) laten een zeer lage overleving in blok 3 zien die mogelijk mede veroorzaakt werd door concurrentie met een populier die boven de esdoorns uitkwam. Heranalyse van de data waarbij selectienummers 191 en 192 uit blok 3 niet meegenomen zijn in de analyse gaf dezelfde conclusie.

Tabel 3 Gemiddelde overleving (\%) van de herkomsten met betrouwbaarheidsintervallen, $p$ waarden van verschil met proefveldgemiddelde, $p<0,05=\left(^{*}\right), p<0,01=*, p<0,001=* *$, $p<0,0001=* * *$.

\begin{tabular}{|c|c|c|c|c|c|c|}
\hline \multirow[b]{2}{*}{ Selnr. } & \multicolumn{6}{|c|}{ Overleving in \% (betrouwbaarheids interval) } \\
\hline & 8 jaar - 2010 & 9 jaar - 2011 & 10 jaar - 2012 & 13 jaar - 2015 & 18 jaar - 2020 & \\
\hline 181 & $98(96-101)$ & $97(94-100)$ & $97(93-100)$ & $87(77-96)$ & $73(60-86)$ & \\
\hline 183 & $100(99-100)$ & $100(99-100)$ & $100(99-100)$ & $93(86-100)$ & $83(72-94)$ & $(*)$ \\
\hline 184 & $96(91-100)$ & $97(94-100)$ & 93 (87-99) & $92(84-100)$ & $77(65-90)$ & \\
\hline 186 & $100(99-100)$ & $100(99-100)$ & $98(96-101)$ & $84(73-95)$ & $60(45-74)$ & \\
\hline 187 & $100(99-100)$ & $100(99-100)$ & $100(99-100)$ & $80(68-92)$ & $54(40-69)$ & \\
\hline 188 & $100(99-100)$ & $100(99-100)$ & $100(99-100)$ & $89(80-98)$ & $71(57-84)$ & \\
\hline 189 & $96(91-100)$ & $97(94-100)$ & $94(89-99)$ & $84(73-95)$ & $60(45-74)$ & \\
\hline 193 & $97(93-100)$ & $97(94-100)$ & $94(89-99)$ & $75(62-87)$ & $46(31-61)$ & $* *$ \\
\hline 194 & $98(96-101)$ & $98(96-101)$ & $97(93-100)$ & $88(79-97)$ & $75(62-87)$ & \\
\hline 195 & $90(84-97)$ & $91(85-97)$ & $86(79-94)$ & $79(67-91)$ & $48(33-62)$ & $* *$ \\
\hline 196 & $100(99-100)$ & $95(90-99)$ & $93(87-99)$ & $84(73-95)$ & $64(50-78)$ & \\
\hline 197 & $98(96-101)$ & $96(92-100)$ & $97(93-100)$ & $87(77-96)$ & $72(59-85)$ & \\
\hline 198 & $98(96-101)$ & $98(96-101)$ & $98(96-101)$ & $93(86-100)$ & $80(68-92)$ & \\
\hline 199 & $98(96-101)$ & $96(92-100)$ & $96(91-100)$ & $92(84-100)$ & $80(68-92)$ & \\
\hline gemiddelde & 98 & 98 & 96 & 86 & 66 & \\
\hline
\end{tabular}




\subsection{Bladuitloop}

Het tijdstip van uitlopen van het blad in het voorjaar is op drie opeenvolgende jaren waargenomen. Zowel in april 2010, 2011 als in 2012 werd een herkomsteffect op het tijdstip van uitlopen waargenomen $(p<0,001)$. In Figuur 4 zijn de klassenverdelingen van de bladuitloop in 2010 weergegeven. De Duitse herkomsten uit Fa. Schmallenberg (selnrs. 191, 192, 193) blijken relatief laat uit te lopen, evenals de zaadgaard Mont Yvoir (199). Van de Duitse herkomsten loopt herkomst Fa. Bad Driburg (selnr. 190) het vroegst uit. De vijf Nederlandse herkomsten verschillen onderling niet of nauwelijks in het tijdstip van uitlopen en ook niet vergeleken met de Belgische herkomsten, met uitzondering van de zaadgaard Mont Yvoir (selnr. 199) die later uitloopt. De rangorde van tijdstip van uitlopen van de herkomsten over de drie jaren is stabiel. Dit betekent dat de relatief vroeg of laat uitlopende herkomsten in 2010 ook relatief vroeg of laat zijn in de overige twee jaren waarin opnames gedaan zijn (Bijlage 6).

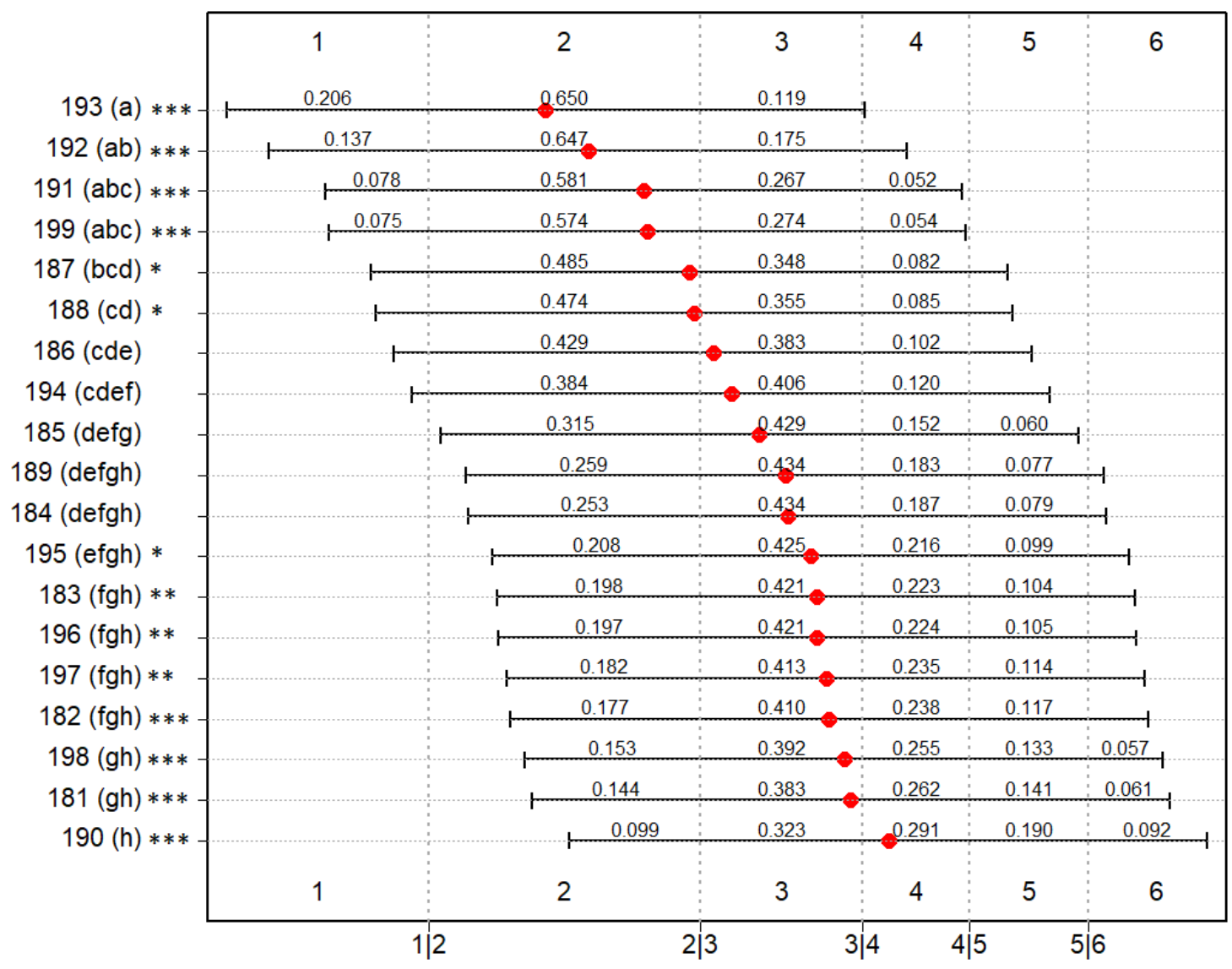

Figuur 4 Bladuitloop van de 19 herkomsten in 2010 met klassenverdeling, gemiddelde score (rode punt), letterdiagram voor paarsgewijze verschillen en $p$-waarden van verschil met proefveldgemiddelde, $p<0,05=(*), p<0,01=*, p<0,001=* *, p<0,0001=* * *$.

\subsection{Groei}

De hoogte werd gemeten op 8-, 13- en 18-jarige leeftijd in respectievelijk 2010, 2015 en 2020. De diameter werd in 2015 en 2020 gemeten. In alle jaren was er een significant effect van herkomst op de groei van de bomen $(p<0,01)$. Op 8-jarige, 13 -jarige en 18 -jarige leeftijd was de gemiddelde hoogte van alle bomen in het proefveld respectievelijk 5,6 m, 10,7 m en 12,8 m. Op 8-jarige en 18-jarige leeftijd was de gemiddelde diameter respectievelijk $6,8 \mathrm{~cm}$ en $8,5 \mathrm{~cm}$ (Tabel 4 ). 
De Nederlandse herkomsten tonen op 18-jarige leeftijd een vergelijkbare diameter als het proefveldgemiddelde (Tabel 4), met uitzondering van Zetten-01 (selnr. 184), die significant dunner is (gemiddeld 6,9 cm, p<0,01). De Duitse herkomsten Fa. Schmallenberg (selnrs. 192 en 193) hebben een significant kleinere diameter dan het proefveldgemiddelde $(p<0,01)$. In 2020 zijn deze verschillen minder groot, maar ligt de diameter van deze herkomsten nog wel ruim $13 \%$ (ruim $1 \mathrm{~cm}$ ) onder het proefveldgemiddelde $(p<0,05)$. De Duitse zaadgaard Mertener Heide (187) heeft een significant grotere diameter dan het proefveldgemiddelde $(10,2 \mathrm{~cm}$ in 2020, $\mathrm{p}<0,01)$. Van de Belgische herkomsten laten Tachètes (selnr. 197) en Grandes Hayes (selnr. 198) de beste diktegroei zien (in beide jaren $10-16 \%$ boven het proefveldgemiddelde).

Wat betreft hoogte zien we vergelijkbare resultaten voor de Nederlandse herkomsten. De Nederlandse herkomsten hebben een hoogtegroei die vergelijkbaar is met het proefveldgemiddelde of iets groter, op Zetten-01 na, die in 2020 een significant lagere groei vertoont $(11,0 \mathrm{~m}, \mathrm{p}<0,001)$. De zaadgaard Mertener Heide (selnr. 187) is de snelst groeiende herkomst met een gemiddelde hoogte van 15,0 m in 2020 ( $p<0,0001$ ). De Duitse herkomsten Kattenbühl (selnr. 186), Fa. Bad Driburg (selnr. 190) en Fa. Schmallenberg (selnr. 193) hebben een minder goede hoogtegroei op oudere leeftijd dan het proefveldgemiddelde $(p<0,05)$. De hoogtegroei van de Belgische herkomsten is vergelijkbaar met het proefveldgemiddelde.

Tabel 4 Gemiddelde diameter en hoogte van de herkomsten met betrouwbaarheidsintervallen en $p$-waarden van verschil met proefveldgemiddelde, $p<0,05=(*), p<0,01=*, p<0,001=* *$ en $p<0,0001=* * *$.

\begin{tabular}{|c|c|c|c|c|c|c|c|}
\hline \multirow[b]{2}{*}{ Selnr. } & \multicolumn{7}{|c|}{ Diameter in cm (betrouwbaarheids interval) Hoogte in $\mathbf{m}$ (betrouwbaarheids interval) } \\
\hline & 13 jaar - 2015 & & 18 jaar - 2020 & & 8 jaar - 2010 & 13 jaar - 2015 & 18 jaar - 2020 \\
\hline 181 & $7.3(6.5-8.0)$ & & $8.7(7.7-9.7)$ & & $6.0(5.1-6.9)$ & $11.6(10.6-12.7)(*)$ & $13.0(12.1-14.0)$ \\
\hline 182 & $7.3(6.5-8.0)$ & & $8.5(7.6-9.5)$ & & $5.9(5.0-6.8)$ & $10.9(9.9-11.9)$ & $13.0(12.1-14.0)$ \\
\hline 183 & $7.5(6.8-8.3)$ & $(*)$ & $9.3(8.4-10.3)$ & & $6.3(5.4-7.1)$ & $11.3(10.3-12.4)$ & $13.9(13.0-14.9)(*)$ \\
\hline 184 & $5.8(5.0 .-6.6)$ & $(*)$ & $6.9(5.9-7.9)$ & $*$ & $5.3(4.4-6.2)$ & $9.5(8.5-10.6)$ & $11.0(10.0-11.9) * *$ \\
\hline 185 & $7.3(6.5-8.0)$ & & $8.7(7.7-9.7)$ & & $5.9(5.0-6.8)$ & $11.3(10.3-12.4)$ & $12.9(12.0-13.9)$ \\
\hline 186 & $6.4(5.6-7.2)$ & & $7.9(6.8-8.9)$ & & $5.3(4.4-6.2)$ & $10.7(9.7-11.8)$ & $11.7(10.6-12.7)\left(^{*}\right)$ \\
\hline 187 & $7.6(6.8-8.5)$ & $(*)$ & $10.2(9.1-11.3)$ & $*$ & $5.9(5.0-6.8)$ & $11.5(10.5-12.6)$ & $15.0(13.9-16.2) * * *$ \\
\hline 188 & $6.5(5.7-7.3)$ & & $8.1(7.1-9.1)$ & & $5.2(4.3-6.1)$ & $10.4(9.4-11.5)$ & $12.7(11.7-13.7)$ \\
\hline 189 & $6.4(5.6-7.2)$ & & $8.5(7.5-9.6)$ & & $5.8(5.0-6.7)$ & $10.4(9.4-11.4)$ & $13.0(11.9-14.1)$ \\
\hline 190 & $6.5(5.7-7.3)$ & & $7.4(6.4-8.5)$ & & $5.7(4.8-6.6)$ & $10.3(9.3-11.4)$ & $11.7(10.7-12.7)\left(^{*}\right)$ \\
\hline 191 & $6.0(5.2-6.8)$ & & $7.9(6.6-9.2)$ & & $5.0(4.1-5.9)$ & $9.9(8.9-11.0)$ & $12.8(11.5-14.0)$ \\
\hline 192 & $5.7(4.9-6.5)$ & $*$ & $7.1(5.7-8.4)$ & $(*)$ & $4.7(3.8-5.6)$ & $(*) 9.6(8.6-10.7)$ & $12.4(11.1-13.7)$ \\
\hline 193 & $5.5(4.7-6.4)$ & $*$ & $7.3(6.1-8.5)$ & $(*)$ & $4.3(3.4-5.1)$ & * $\quad 9.7(8.7-10.8)$ & $11.4(10.2-12.6)(*)$ \\
\hline 194 & $6.6(5.8-7.4)$ & & $7.6(6.6-8.6)$ & & $5.8(4.9-6.7)$ & $10.7(9.7-11.7)$ & $12.5(11.5-13.5)$ \\
\hline 195 & $6.4(5.6-7.2)$ & & $9.2(8-10.4)$ & & $5.0(4.1-5.9)$ & $10.2(9.1-11.2)$ & $13.1(11.9-14.3)$ \\
\hline 196 & $6.6(5.8-7.4)$ & & $8.5(7.4-9.5)$ & & $5.0(4.1-5.9)$ & $10.3(9.3-11.3)$ & $12.7(11.6-13.7)$ \\
\hline 197 & $7.5(6.7-8.3)$ & $(*)$ & $9.6(8.6-10.6)$ & $(*)$ & $6.0(5.1-6.9)$ & $11.0(10.0-12.0)$ & $13.5(12.5-14.5)$ \\
\hline 198 & $7.9(7.1-8.7)$ & $*$ & $9.8(8.9-10.8)$ & $*$ & $6.7(5.8-7.6)$ & * $\quad 11.7(10.7-12.8)(*)$ & $13.4(12.5-14.4)$ \\
\hline 199 & $7.1(6.3-7.9)$ & & $8.9(7.9-9.8)$ & & $6.0(5.1-6.9)$ & $11.1(10.1-12.1)$ & $13.3(12.3-14.2)$ \\
\hline gemiddelde & 6,8 & & 8,5 & & 5,6 & 10,7 & 12,8 \\
\hline $\max$ & 7,9 & & 10,2 & & 6,7 & 11,7 & 15,0 \\
\hline $\min$ & 5,6 & & 6,9 & & 4,3 & 9,6 & 10,9 \\
\hline
\end{tabular}



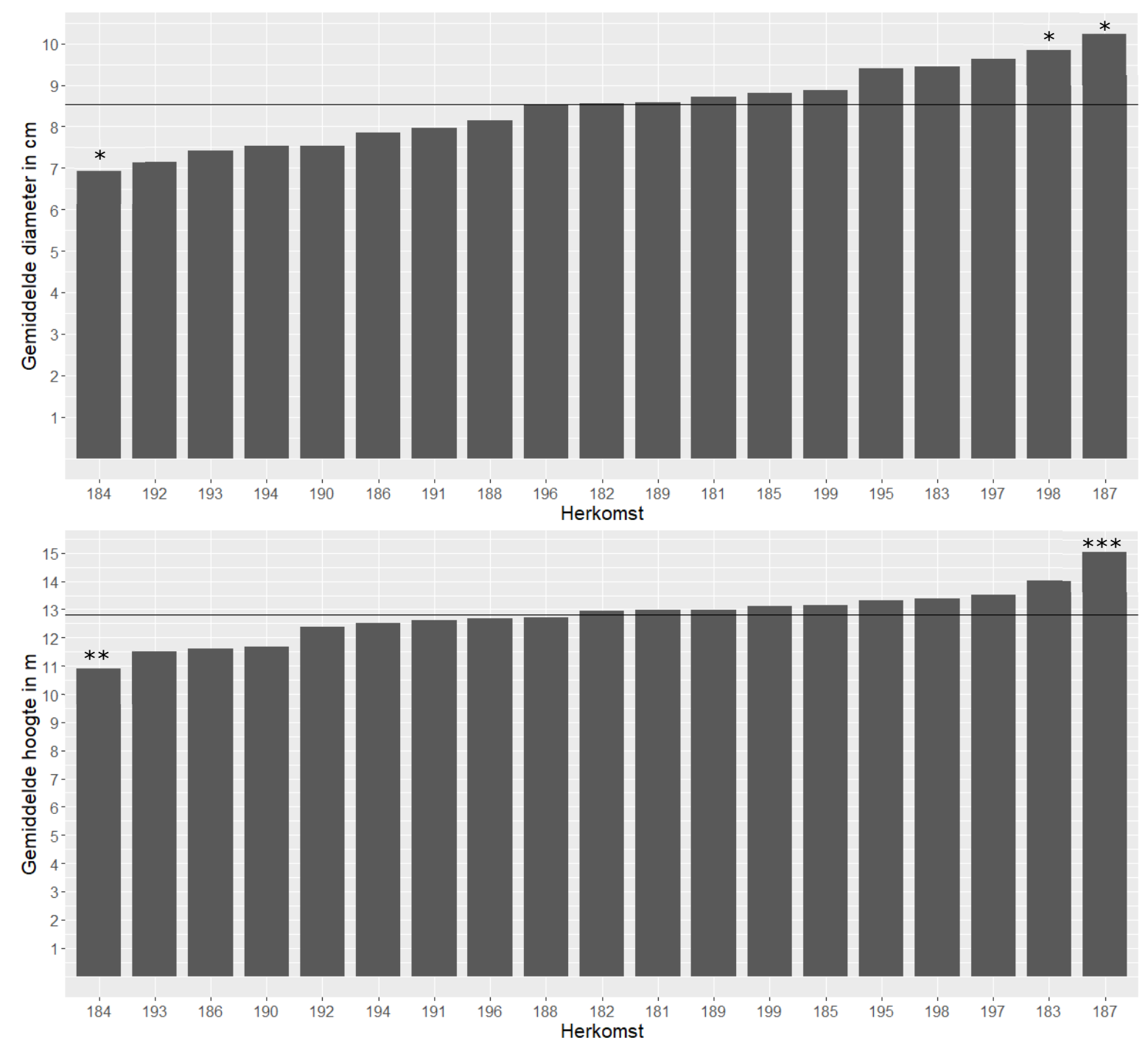

Figuur 5 Herkomstgemiddelde voor diameter en hoogte op 18-jarige leeftijd (2020) gesorteerd van klein naar groot, met proefveldgemiddelde weergegeven als lijn, $p$-waarden van verschil met proefveldgemiddelde, $p<0,01=*, p<0,001=* *, p<0,0001=* * *$.

\subsection{Vorm}

In 2020 is de boomvorm op basis van stamrechtheid en aanwezigheid en positie van vorken beoordeeld. De stamrechtheid en vorken werd beoordeeld in vijf klassen op een ordinale schaal van slecht (1) naar goed (5) (Bijlage 4 en 5). Er werden voor rechtheid geen bomen aangetroffen in klasse 1 (struikvorm), zodat de analyses met de resterende vier klassen zijn uitgevoerd. In Figuur 6 en 7 worden de resultaten van stamvorm en vorken getoond.

Er bleek een significant effect van herkomst op stamvorm te zijn $(p<0,001)$. De Nederlandse herkomsten Zeewolde-01 en Geldermalsen-01 (selnrs. 183 en 185) hebben een significant betere stamvorm dan het proefveldgemiddelde. De Duitse herkomsten Fa. Schmallenberg (selnr. 193), Roddergrube (selnr. 188) en Bad Driburg (selnr. 190) scoren het laagst, waarvan 190 significant lager $(p<0.01)$ en 193 en 188 met een $p<0.05$. Deze Duitse herkomsten vallen voor meer dan $70 \%$ in klasse 2 'matig tot sterk gebogen stam', terwijl de beste Nederlandse herkomsten Zeewolde-01 (selnr. 183) en Geldermalsen-01 (selnr. 185) voor ca. 50\% in klasse 3 'licht tot matig gebogen stam in meerdere richtingen' vallen. De Nederlandse herkomsten Geldermalsen-01 (selnr. 185), Zeewolde01 (selnr. 183), Vaartbos-01 (selnr. 181) en de Duitse zaadgaard Kattenbühl (selnr. 186) hebben ook een betere stamvorm t.o.v. het proefveldgemiddelde $(p<0,05$ en $p<0,01)$. 
Voor de aanwezigheid en positie van vorken was er een klein significant effect van herkomst $(p<0,05)$, al worden er in de paarsgewijze analyse geen significante verschillen gevonden tussen de herkomsten. Fa. Schmallenberg en Sartage (selnrs. 193 en 196) hebben een significant lagere score dan gemiddeld $(p<0,01)$. Bij alle herkomsten valt minstens $59 \%$ van de bomen in klasse 5 (geen vorken).

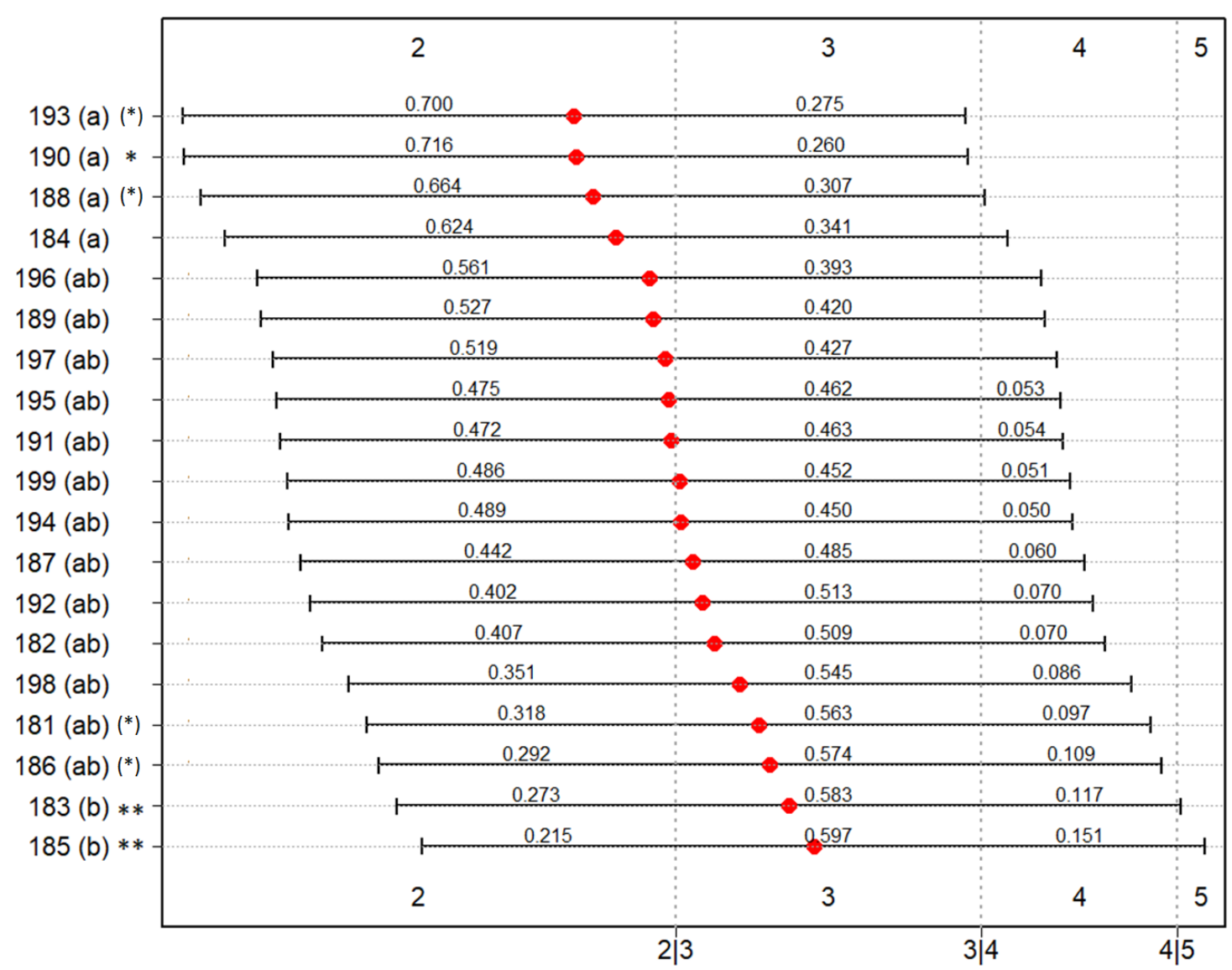

Figuur 6 Rechtheid van de stam op 18-jarige leeftijd met klassenverdeling, gemiddelde score (rode punt), letterdiagram voor paarsgewijze verschillen en $p$-waarden voor verschil met proefveldgemiddelde, $p<0,05=(*), p<0,01=*, p<0,001=* *, p<0,0001=* * *$. 


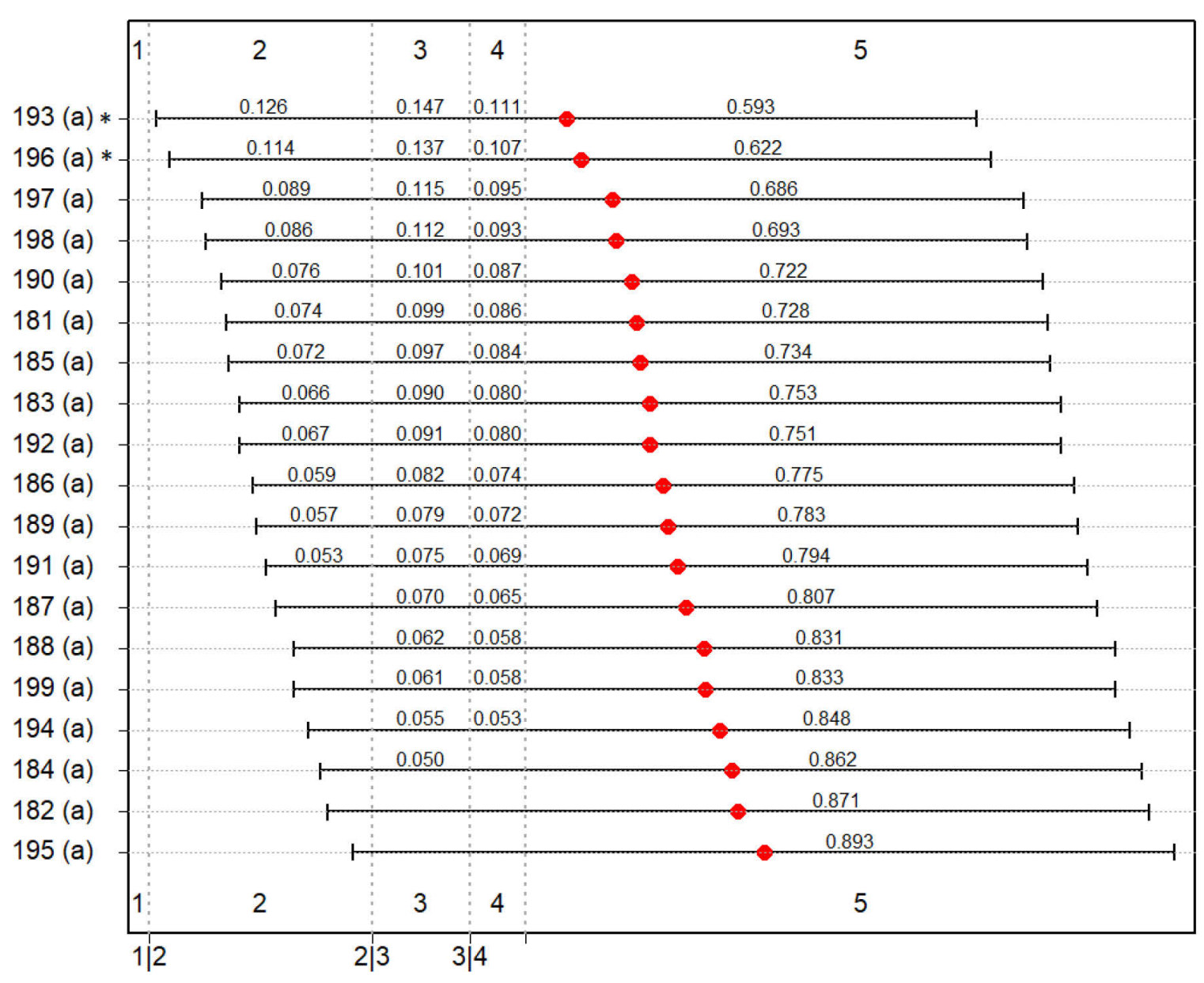

Figur 7 Aanwezigheid vorken op 18-jarige leeftijd met klassenverdeling, gemiddelde score (rode punt), letterdiagram voor paarsgewijze verschillen en $p$-waarden voor verschil met proefveldgemiddelde, $p<0,05=(*), p<0,01=*, p<0,001=* *, p<0,0001=* * *$.

\subsection{Jaarringonderzoek}

Uit zowel de jaarringbreedtes als de cumulatieve oppervlakte van de stamdoorsnede blijkt dat de herkomst Fa. Schmallenberg (selnr. 193) gedurende de gehele periode (2003-2019) de minste groei vertoont en dat de groei van herkomst Grandes Hayes (selnr. 198) systematisch boven die van de twee andere herkomsten ligt (Figuur 8). Kijkend naar de groeidynamiek over de tijd is duidelijk dat de gemiddelde jaarringbreedte van de drie herkomsten na aanplant in 2004 snel toeneemt naar maximale waarden rond 2008 en daarna in alle drie herkomsten geleidelijk afneemt (Figuur 8). In 2018, het jaar met de extreme droogte, vertonen de bomen van alle herkomsten een duidelijke groeidepressie met een sterke afname van de gemiddelde jaarringbreedtes ten opzichte van de jaren 2015-2017. De resistance index bedraagt respectievelijk $0.42,0.43$ en 0.58 voor Vaartbos-01 (selnr. 181), Fa. Schmallenberg (selnr. 193) en Grandes Hayes (selnr. 198). In 2019 is de groei (recovery) ten opzichte van 2018 in alle drie herkomsten weer toegenomen met waarden voor de recovery index van respectievelijk 2.08, 1.67 en 1.66 . De groei van 2019 is afhankelijk van herkomst lager tot bijna hetzelfde als de groei in de periode 2015-2017 voor de droogte, met waarden voor de resilience index van respectievelijk $0.88,0.73$ en 0.96 . 

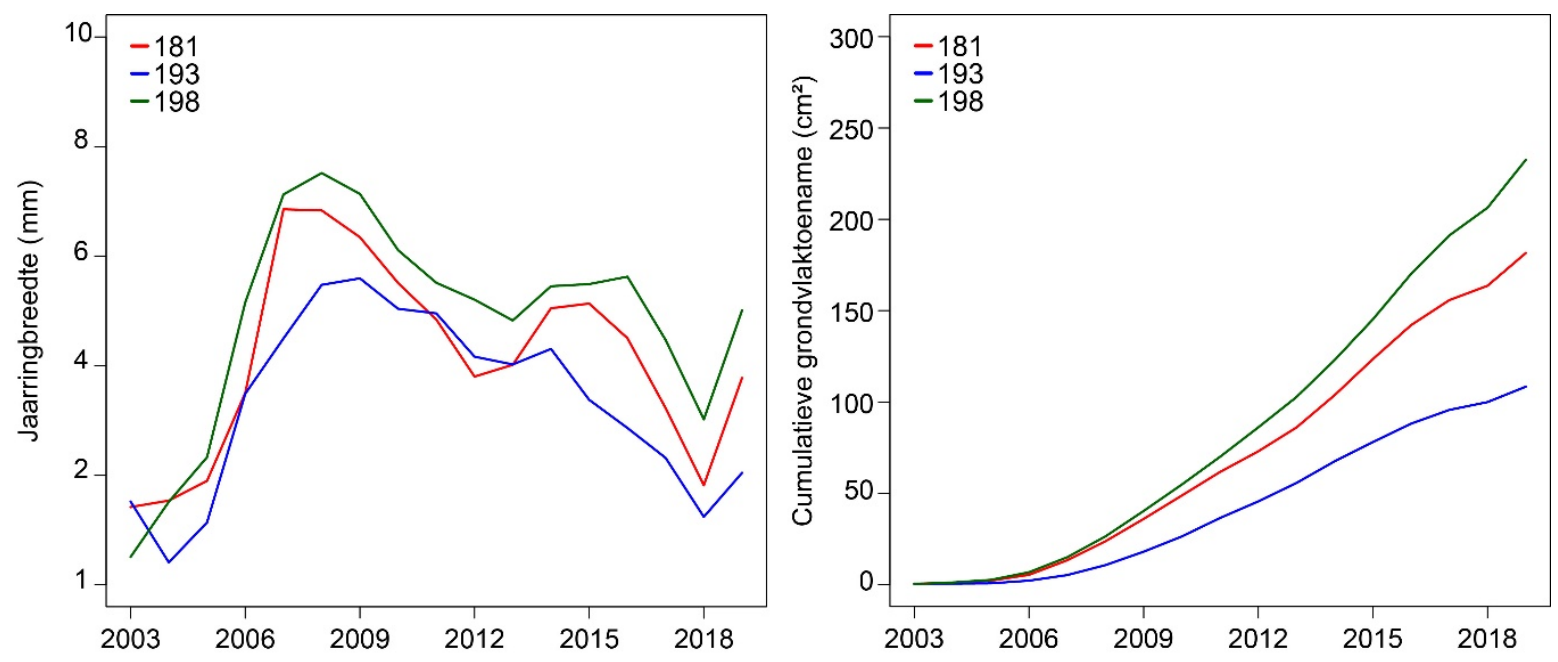

Figuur $8 \quad$ Groei van de drie onderzochte herkomsten van Acer pseudoplatanus met links de gemiddelde jaarringbreedtes en rechts de gemiddelde cumulatieve groei in oppervlakte van de stamdoorsnede. 


\section{Discussie \& aanbevelingen}

Het doel van dit onderzoek naar gewone esdoorn (Acer pseudoplatanus) was om op basis van een vergelijkende toetsproef inzicht te krijgen in de kwaliteit en aangepastheid van buitenlandse herkomsten ten opzichte van Nederlandse herkomsten. Hieronder worden conclusies getrokken op basis van de resultaten van overleving, hoogte- en diametergroei, tijdstip van uitlopen en vorm gemeten aan de herkomsten. Op basis van de resultaten worden aanbevelingen gedaan over het gebruik van deze buitenlandse herkomsten voor aanplant in Nederland.

\subsection{Kwaliteit en aangepastheid van de herkomsten}

De resultaten laten zien dat de overleving op jonge leeftijd van alle herkomsten goed is. Op 13 jaar oude leeftijd (2015) varieert de overleving van de herkomsten tussen $75 \%$ en $93 \%$ en worden er geen significante verschillen gevonden. Op een leeftijd van 18 jaar is de gemiddelde overleving duidelijk lager $(66 \%)$ en zijn er significante verschillen tussen de herkomsten qua overleving. Naast dit herkomsteffect wordt de lagere overleving in het gehele proefveld in 2020 voornamelijk verklaard door de sluiting van het kronendak en toenemende concurrentie tussen individuen (stakenfase) in deze ongedunde herkomstenproef.

Op 8-, 13- en 18-jarige leeftijd worden er significante verschillen in groei tussen de negentien getoetste esdoorn-herkomsten gevonden. De herkomsten variëren van gemiddeld $85 \%(10,9 \mathrm{~m})$ tot $117 \%(15,0 \mathrm{~m})$ van het proefveldgemiddelde voor hoogte op een leeftijd van 18 jaar (Tabel 5). Voor diameter loopt de gemiddelde groei uiteen van $81 \%(6,9 \mathrm{~cm})$ tot $120 \%(10,2 \mathrm{~cm})$ van het proefveldgemiddelde. Dit zijn redelijke tot aanzienlijke verschillen in groei en interessant om rekening mee te houden wanneer productie één van de doelstellingen in het beheer is. Ook worden er significante verschillen in tijdstip van uitlopen aangetoond. De variatie in vorm (rechtheid van de stam en vorken) tussen de herkomsten op 18-jarige leeftijd is niet groot. Alle herkomsten laten een matige stamvorm zien met een hoog percentage bomen in klasse 2 en 3, maar geen of nauwelijks vorken (hoog percentage bomen in klasse 5). 
Tabel 5 Samenvatting van de resultaten voor overleving, groei, vorm in 2020 en bladuitloop (data 2010) van de 19 herkomsten. Voor overleving, hoogte en diameter zijn de herkomstgemiddelden als \% van het proefveldgemiddelde weergegeven.

\begin{tabular}{|c|c|c|c|c|c|c|c|}
\hline Selnr. & $\begin{array}{l}\text { Land van } \\
\text { herkomst }\end{array}$ & Herkomstnaam & Overleving & Diameter & logte & Rechtheid Vorken & Bladuitloop \\
\hline 181 & $\mathrm{NL}$ & Vaartbos-01 & $110 \%$ & $102 \%$ & $100 \%$ & $*$ & vroeger* \\
\hline 183 & $\mathrm{NL}$ & Zeewolde-01 & $126 \%$ & $110 \%$ & $109 * \%$ & $*$ & vroeger* \\
\hline 184 & $\mathrm{NL}$ & Zetten-01 & $116 \%$ & $81 * \%$ & $85 * \%$ & & \\
\hline 186 & $\mathrm{D}$ & SP Kattenbühl & $92 \%$ & $91 \%$ & $90 \%$ & & \\
\hline 187 & $\mathrm{D}$ & SP Mertener Heide & $83 \%$ & $120 * \%$ & $117 * \%$ & & later* \\
\hline 188 & $\mathrm{D}$ & SP Roddergrube & $107 \%$ & $95 \%$ & $99 \%$ & & later* \\
\hline 189 & $\mathrm{D}$ & Fa. Mettmann & $92 \%$ & $100 \%$ & $100 \%$ & & \\
\hline 192 & $\mathrm{D}$ & $\begin{array}{l}\text { Fa. Schmallenberg, Staatswald } \\
\text { Abt. 84A, 84B }\end{array}$ & $56 * \%$ & $84 \%$ & $96 \%$ & & later* \\
\hline 193 & $\mathrm{D}$ & $\begin{array}{l}\text { Fa. Schmallenberg, Staatswald } \\
\text { Abt. 85B }\end{array}$ & $71 * \%$ & $87 \%$ & $90 \%$ & & later* \\
\hline 194 & $\mathrm{D}$ & SP Grohnde & $115 \%$ & $88 \%$ & $97 \%$ & & \\
\hline 195 & $\mathrm{~B}$ & Konenbos & $74 * \%$ & $109 \%$ & $103 \%$ & & vroeger* \\
\hline 196 & $\mathrm{~B}$ & Sartage & $98 \%$ & $100 \%$ & $98 \%$ & & vroeger* \\
\hline 197 & B & Tachètes & $109 \%$ & $113 \%$ & $105 \%$ & & vroeger* \\
\hline 198 & $\mathrm{~B}$ & Grandes Hayes & $121 \%$ & $115 * \%$ & $103 \%$ & & vroeger* \\
\hline
\end{tabular}

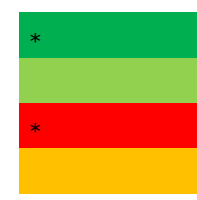

significant beter dan proefveldgemiddeld $(p<0,01)$

significant beter dan proefveldgemiddelde $(p<0,05)$

significant slechter dan proefveldgemiddelde $(p<0,01)$

significant slechter dan proefveldgemiddelde $(p<0,05)$

vroeger* t.o.v. proefveldgemiddeld $(p<0,01)$

later* t.o.v. proefveldgemiddelde $(p<0,01)$

\subsubsection{Nederlands herkomsten}

De Nederlandse herkomsten verschillen onderling niet of nauwelijks qua overleving en tijdstip van uitlopen. De overleving is goed. De Nederlandse herkomsten lopen relatief vroeg uit, vroeger dan het proefveldgemiddelde, behalve Zetten-01 (selnr. 184) en Geldermalsen (selnr. 185). De herkomsten presteren goed qua groei (beter of vergelijkbaar met het proefveldgemiddelde), met uitzondering van de zaadgaard Zetten-01 (selnr. 184) die achterblijft in zowel hoogte- als diametergroei (Tabel 5). Daarnaast hebben Geldermalsen (selnr. 185) en Zeewolde-01 (selnr. 183) de beste scores voor rechtheid. De genetische samenstelling van de vier zaadgaarden is verschillend en overlapt qua klonensamenstelling slechts voor een klein deel. Dit kan een verklaring zijn voor het grote verschil tussen de zaadgaard Zetten-01 (selnr. 184) en de andere zaadgaarden.

\subsubsection{Duitse herkomsten}

De Duitse herkomsten presteren zeer variabel. De meeste Duitse autochtone herkomsten lijken later uit te lopen dan de Nederlandse herkomsten. Dit is vooral duidelijk bij de herkomsten Fa. Schmallenberg (selnrs. 191, 192 \& 193), de zaadgaard Roddergrube (selnr. 188), alle afkomstig uit herkomstgebied 80104 (Westdeutsches Bergland, montane Stufe) en de zaadgaard Mertener Heide (selnr. 187). Voor een soort die gevoelig is voor late nachtvorst is laat uitlopen een gunstige eigenschap. De zaadgaard Mertener Heide (selnr. 187) is de best presterende herkomst voor zowel hoogte- als diametergroei en presteert op andere eigenschappen voldoende (gemiddeld). De overige zaadgaarden presteren gemiddeld voor alle eigenschappen (SP Grohnde, selnr. 194) of matig op één 
van de eigenschappen (SP Kattenbühl, selnr. 186 en SP Roddergrube, selnr. 188). De herkomsten Fa. Schmallenberg (selnrs. 191, 192 \& 193) laten een slechte overleving zien op oudere leeftijd. Deze autochtone herkomsten, alle afkomstig uit dicht naast elkaar gelegen bosgebieden in het Fa. Schmallenberg, presteren gemiddeld tot matig voor groei en vorm. De autochtone herkomst Bad Driburg (selnr. 190) presteert eveneens matig voor hoogtegroei en slecht voor stamrechtheid, terwijl de niet-autochtone herkomst Mettmann (selnr. 189) gemiddeld presteert voor alle eigenschappen. Beide zijn afkomstig uit herkomstgebied 80103 (Westdeutsches Bergland, kolline Stufe).

De herkomstgebieden 80403 en 80404 worden gekenmerkt door een oceanisch tot sub-oceanisch berglandklimaat, waarbij de vorst toeneemt met de hoogte (BLE, 2020). Met herkomstgebied 80104 worden de hoger gelegen opstanden van esdoorn in de West-Duitse hooglanden afgebakend van het herkomstgebied 801 03. Deze hoger gelegen delen in 80104 liggen veelal boven 400 m (BLE, 2020). Esdoorns uit deze opstanden onderscheiden zich met hun fenotypisch aangepaste, minder uitstekende kroonvorm, aangepast aan het risico van sneeuw- en ijsbreuk (BLE, 2020). Verschillen in groei, overleving en tijdstip van uitlopen tussen opstanden in hoge en lagere gebieden kunnen duiden op lokale aanpassing aan bijvoorbeeld de lengte van het groeiseizoen. Ook zijn herkomsten uit lagere gebieden mogelijk aangepast aan een milder klimaat en geselecteerd op groei, terwijl herkomsten uit hoger gelegen gebieden mogelijk een betere koude-tolerantie hebben.

\subsubsection{Belgische herkomsten}

De meeste Belgische herkomsten hebben een vergelijkbaar tijdstip van bladuitloop als de Nederlandse zaadgaarden (Vaartbos-01, -02) en herkomst Zeewolde-01 (vroeger dan het proefveldgemiddelde). De Walloonse zaadgaard Mont Yvoir (199) is later uitlopend, wat als een gunstige eigenschap wordt gezien. Voor de overige eigenschappen presteren de Belgische herkomsten goed, met als uitzondering dat de herkomst Konenbos (195) een lagere overleving op 18-jarige leeftijd heeft en Sartage (selnr. 196) meer lage vorken dan het proefveldgemiddelde. De twee Walloonse herkomsten Tachètes (selnr. 197) en Grandes Hayes (selnr. 198) zijn afkomstig uit Lotharingen en liggen op aanzienlijke hoogte (350-360 m) vergeleken met Nederland. Aangezien bij aanbevelingen voor aanplant in Vlaanderen een hoogteligging van $300 \mathrm{~m}$ als bovengrens gehanteerd wordt, staan deze herkomsten in Vlaanderen niet op de lijst van aanbevolen herkomsten. De resultaten uit de herkomstenproef geven echter aan dat deze herkomsten het goed lijken te doen in Nederland.

\subsection{Effect van de 2018 droogte op groei van gewone esdoorn}

Op basis van het jaarringonderzoek blijkt dat drie herkomsten van gewone esdoorn een duidelijke groeidepressie laten zien in het extreem droge jaar 2018. Afhankelijk van de herkomst was de gemiddelde afname in radiale groei tussen 42 en 58\% ten opzichte van de jaren 2015-2017. De productiefste herkomst (Grandes Hayes, selnr. 198) had de hoogste resistance en de hoogste resilience en groeide in 2019 bijna weer op hetzelfde niveau als in de jaren 2015-2017 voor de droogte. Vaartbos-01 (selnr. 181) had een lagere resistance (0.42), maar had de hoogste recovery (2.08). De minst productieve herkomst Fa. Schmallenberg (selnr. 193) had de laagste resilience (0.73) en groeide in 2019 nog steeds $27 \%$ minder dan in de periode 2015-2017.

Ook in andere onderzoeken is gevonden dat esdoorn sensitief reageert op droogte. Heklau et al. (2019) bestudeerden de groeireactie van gewone esdoorn, zomereik en haagbeuk met behulp van jaarringonderzoek in het extreem droge jaar 1976 in Centraal Duitsland. Ze vonden dat ten opzichte van zomereik en haagbeuk de gewone esdoorn een sterkere groeiafname (lage resistance) vertoonde in het jaar van de droogte, maar ook het beste herstelde (recovery) na de droogte. De verhouding tussen de groei van de gewone esdoorn na de droogte en voor de droogte (resilience) was wel lager vergeleken met de zomereik en haagbeuk. Dit kan wijzen op de vaker beschreven lagere droogtetolerantie van de gewone esdoorn (Gebauer et al., 2008; Köcher et al., 2009; Scherrer et al., 2011) in vergelijking met zomereik en haagbeuk. Scharnweber et al. (2020) onderzochten het effect van de 2018/2019-droogte op de groei van de gewone esdoorn in Noordoost-Duitsland en vonden dat de groeiafname in 2018 
minder sterk was dan in het eveneens droge jaar 2019, waarin de jaarringbreedte met ca. 30\% afnam. De groeiomstandigheden in het Horsterwold met kleigronden en relatief hoge grondwaterstanden, maar verwachte ondiepe beworteling zorgen ervoor dat de bodem in droogtejaren, zoals 2018, relatief snel uitdroogt waardoor de esdoorns watertekort ervaren. Dit is ook beschreven door Weemstra et al. (2013) voor esdoorn en negen andere soorten groeiende op een vergelijkbare standplaats in de Flevopolder. In 2018 begon het watertekort relatief vroeg in het groeiseizoen. De bomen sluiten uiteindelijk hun huidmondjes om waterverlies te voorkomen en stoppen met groeien, wat leidt tot een smalle jaarring (Scherrer et al., 2011). Het goede groeiherstel (recovery) van de esdoorns in 2019, in tegenstelling tot de resultaten voor Noordoost-Duitsland, heeft te maken met de verbeterde waterbeschikbaarheid in het Horsterwold na de droogte. De bodems raakten gedurende de winter en het voorjaar weer meer waterverzadigd, wat voor gunstige groeicondities zorgde, althans in het begin van het groeiseizoen van 2019. Daarmee bevestigen onze resultaten van het jaarringonderzoek van de drie herkomsten van gewone esdoorn het beeld dat de soort sensitief reageert op droogte, maar dat deze - als de waterbeschikbaarheid na het droogtejaar verbetert - ook snel in groei kan herstellen.

\subsection{Aanbevelingen Rassenlijst Bomen}

De herkomsten in dit onderzoek zijn slechts op één locatie in Nederland getoetst en onder optimale bodemcondities. De twintig grootste bomen per herkomst hadden een hoogte op 18-jarige leeftijd die varieerde tussen 13,5 en 17,0 m (Bijlage 7). Dit is vergelijkbaar of hoger dan verwacht wordt op grond van boniteit 1 in de opbrengsttabellen (Jansen et al., 2018). Eerder onderzoek uit Engeland laat zien dat herkomstverschillen mogelijk minder duidelijk zijn onder gunstige groeicondities en groter onder meer stressvolle omstandigheden (Cundall et al., 1998). Bij voorkeur worden herkomsten dan ook getest op meerdere en contrasterende locaties.

\subsubsection{Nederlandse herkomsten}

De Nederlandse zaadgaarden en herkomst Geldermalsen-01 zijn alle toegelaten tot de Rassenlijst Bomen. De zaadgaard Vaartbos-02 is in 2019 gerooid. De klonen uit deze zaadgaard die niet voorkomen in Vaartbos-01 worden gekopieerd en toegevoegd aan Vaartbos-01. Te zijner tijd kan deze nieuwe, samengestelde zaadgaard in de Rassenlijst worden opgenomen. De groei van Zetten-01 (selnr. 184) blijft ver achter bij de overige zaadgaarden en ook ten opzichte van de selectieopstand Geldermalsen-01 (185). Aanbevolen wordt bij voldoende beschikbaarheid van zaad de voorkeur te geven aan materiaal uit de zaadgaarden Vaartbos-01/-02, Zeewolde-01 en de selectieopstand Geldermalsen-01.

\subsubsection{Duitse herkomsten}

Op grond van de resultaten uit deze herkomstenproef concluderen we dat de vier buitenlandse zaadgaarden Mertener Heide (selnr. 187), Kattenbühl (selnr. 186), Roddergrube (selnr. 188) en Grohnde (selnr. 194) kunnen worden aanbevolen voor aanplant in Nederland. Van deze vier zaadgaarden zou de voorkeur gegeven kunnen worden aan materiaal uit de zaadgaard Mertener Heide (selnr. 187) vanwege de zeer goede groei-eigenschappen.

Op basis van de resultaten van deze toetsproef blijkt geselecteerd materiaal (categorie 'S'), geoogst in Fa. Schmallenberg (onderdeel van het herkomstgebied 801 04), minder geschikt voor aanplant in Nederland. De twee opstanden Fa. Mettmann en Fa. Bad Driburg uit herkomstgebied 80103 presteren verschillend; Fa. Bad Driburg voldoet niet in voldoende mate aan alle gewenste eigenschappen (o.a. matige stamrechtheid) en wordt niet aanbevolen voor aanplant in Nederland. Fa. Mettmann presteert gemiddeld en kan worden aanbevolen voor gebruik in Nederland.

\subsubsection{Belgische herkomsten}

De twee Belgische opstanden Tachètes en Grandes Hayes en de zaadgaard Mont-Yvoir kunnen alle aanbevolen worden voor aanplant in Nederland. Op basis van de resultaten van deze toets worden Konenbos en Sartage niet aanbevolen, omdat zij niet in voldoende mate aan alle gewenste goede eigenschappen voldoen. 


\section{Literatuur}

BINGGELI, P. 1993. The conservation value of sycamore. Quarterly Journal of Forestry, 87.

BLE. 2020. Nationales Inventar, Bergahorn 8. Acer pseudoplatanus L. Bergahorn [Online]. Available: https://fgrdeu.genres.de/index.php?id=1685\&L=0 [Accessed 12-10-2020 2020].

CARÓN, M. M., DE FRENNE, P., CHABRERIE, O., COUSINS, S. A. O., DE BACKER, L., DECOCQ, G., DIEKMANN, M., HEINKEN, T., KOLB, A., NAAF, T., PLUE, J., SELVI, F., STRIMBECK, G. R., WULF, M. \& VERHEYEN, K. 2015. Impacts of warming and changes in precipitation frequency on the regeneration of two Acer species. Flora - Morphology, Distribution, Functional Ecology of Plants, 214, 24-33.

CAUDULLO, G., WELK, E. \& JSUS, S.-M.-A. 2017. Chorological maps for the main European woody species. Data in Brief 12, 662-666. DOI: doi.org/10.1016/j.dib.2017.05.007.

CLAESSENS, H., PAUWELS, D., THIBAUT, A. \& RONDEUX, J. 1999. Site index curves and autecology of ash, sycamore and cherry in Wallonia (Southern Belgium). Forestry: An International Journal of Forest Research, 72, 171-182.

CUNDALL, E. P., CAHALAN, C. M. \& PLOWMAN, M. R. 1998. Early results of sycamore (Acer pseudoplatanus) provenance trials at farm-forestry sites in England and Wales. Forestry, 71, 237-245.

DAWS, M. I. \& PRITCHARD, H. W. 2008. The development and limits of freezing tolerance in Acer pseudoplatanus fruits across Europe is dependent on provenance. Cryo letters, 29, 189-98.

DE KEERSMAEKER, L., DE HAECK A., DE VOS B., LEYMAN A., ROSKAMS P., THOMAES A., VAN DER AA B. \& K., V. 2016. De ecologische positie van gewone esdoorn (Acer pseudoplatanus) en de mogelijkheden van deze boomsoort in landschaps- en bosbeheer. Rapporten van het Instituut voor Natuur- en Bosonderzoek (INBO.R.2016.12186866). Brussel: De ecologische positie van gewone esdoorn (Acer pseudoplatanus) en de mogelijkheden van deze boomsoort in landschaps- en bosbeheer.

DESIE, E., VANCAMPENHOUT, K., NYSSEN, B., VAN DEN BERG, L., WEIJTERS, M., VAN DUINEN, G.-J., DEN OUDEN, J., VAN MEERBEEK, K. \& MUYS, B. 2020. Litter quality and the law of the most limiting: Opportunities for restoring nutrient cycles in acidified forest soils. Science of The Total Environment, 699, 134383.

EUROPEAN COMMISSION, D. S. 2015. FOREMATIS - Forest Reproductive Material Information System [Online]. [Accessed 22-09-2020].

GEBAUER, T., HORNA, V. \& LEUSCHNER, C. 2008. Variability in radial sap flux density patterns and sapwood area among seven co-occurring temperate broad-leaved tree species. Tree Physiology, 28, 1821-1830.

HANEWINKEL, M., CULLMANN, D. A., SCHELHAAS, M.-J., NABUURS, G.-J. \& ZIMMERMANN, N. E. 2013. Climate change may cause severe loss in the economic value of European forest land. Nature Climate Change, 3, 203-207.

HeIN, S., COllet, C., AMMER, C., GOFF, N. L., SKOVSGAARD, J. P. \& SAVILL, P. 2008. A review of growth and stand dynamics of Acer pseudoplatanus L. in Europe: implications for silviculture. Forestry: An International Journal of Forest Research, 82, 361-385.

HEKLAU, H., JETSCHKE, G., BRUELHEIDE, H., SEIDLER, G. \& HAIDER, S. 2019. Species-specific responses of wood growth to flooding and climate in floodplain forests in Central Germany. iForest - Biogeosciences and Forestry, 12, 226-236.

INBO. 2020. Lijst van aanbevolen herkomsten van inheemse boom- en struiksoorten [Online]. [Accessed].

JANSEN, J., OOSTERBAAN, A., MOHREN, G. \& DEN OUDEN, J. 2018. Groei en productie van gewone esdoorn in Nederland. Wageningen University \& Research.

KLAASSEN, R., LERINK, B.J.W., SASS-KLAASSEN, U.G.W. COPINI, P., DEN OUDEN, J. \& KUPERS, P. I. M. O. 2021. Bosontwikkeling en houtproductie langs infrastructuur. Vakblad Natuur, Bos \& Landschap, April \#174, 16-20 
KÖCHER, P., GEBAUER, T., HORNA, V. \& LEUSCHNER, C. 2009. Leaf water status and stem xylem flux in relation to soil drought in five temperate broad-leaved tree species with contrasting water use strategies. Annals of Forest Science, 66, 101.

KRABEL, D. \& WOLF, H. 2013. Sycamore Maple (Acer pseudoplatanus L.). In: PÂQUES, L. E. (ed.) Forest Tree Breeding in Europe: Current State-of-the-Art and Perspectives. Dordrecht: Springer Netherlands.

KUPERS, P. I. M. O., J. DEN; SASS-KLAASSEN, U.G.W.; COPINI, P.; LERINK, B.J.W.; HEKHUIS, HARRIE; GÖTZ, MIREILLE; KLAASSEN, R. 2020. Bosontwikkeling en houtproductie langs infrastructuur.

LINDENBERGH, D. G. K., G. 2020. Revitalisering laagproductief bos. Bosgroep Midden Nederland.

LLORET, F., KEELING, E. G. \& SALA, A. 2011. Components of tree resilience: effects of successive lowgrowth episodes in old ponderosa pine forests. Oikos, 120, 1909-1920.

MITCHELL, R. J., BEATON, J. K., BELLAMY, P. E., BROOME, A., CHETCUTI, J., EATON, S., ELLIS, C. J., GIMONA, A., HARMER, R., HESTER, A. J., HEWISON, R. L., HODGETTS, N. G., IASON, G. R., KERR, G., LITTLEWOOD, N. A., NEWEY, S., POTTS, J. M., POZSGAI, G., RAY, D., SIM, D. A., STOCKAN, J. A., TAYLOR, A. F. S. \& WOODWARD, S. 2014. Ash dieback in the UK: A review of the ecological and conservation implications and potential management options. Biological Conservation, 175, 95-109.

MORECROFT, M. D., STOKES, V. J., TAYLOR, M. E. \& MORISON, J. I. L. 2008. Effects of climate and management history on the distribution and growth of sycamore (Acer pseudoplatanus L.) in a southern British woodland in comparison to native competitors. Forestry: An International Journal of Forest Research, 81, 59-74.

OLSTHOORN, A. F. M., KOSTER, A., SLIM, P. A. \& KOOP, H. G. M. J. 2001. Het effect van gewone esdoorn op de diversiteit van bos: een oriënterende studie. Wageningen: Alterra, Research Instituut voor de Groene Ruimte.

PASTA, S., RIGO, D. \& CAUDULLO, G. 2016. Acer pseudoplatanus in Europe: distribution, habitat, usage and threats. European Atlas of Forest Tree Species, e01665a.

PETERKEN, G. F. 2001. Ecological effects of introduced tree species in Britain. Forest Ecology and Management, 141, 31-42.

ROSKAMS, P. D. H., A. 2021. Advies over de roetschorsschimmel.

RUSANEN, M. \& MYKING, T. 2003. EUFORGEN Technical Guidelines for genetic conservation and use for Sycamore (Acer pseudoplatanus), Bioversity International.

SCHARNWEBER, T., SMILJANIC, M., CRUZ-GARCÍA, R., MANTHEY, M. \& WILMKING, M. 2020. Tree growth at the end of the 21st century - the extreme years 2018/19 as template for future growth conditions. Environmental Research Letters, 15, 074022.

SCHELHAAS, M., CLERKX, A. P. P. M., DAAMEN, W. P., OldENBURGER, J. F., VelemA, G., SCHNITGER, P., SCHOONDERWOERD, H. \& KRAMER, H. 2014. Zesde Nederlandse bosinventarisatie: methoden en basisresultaten. Wageningen: Alterra, Wageningen-UR.

SCHERRER, D., BADER, M. K.-F. \& KÖRNER, C. 2011. Drought-sensitivity ranking of deciduous tree species based on thermal imaging of forest canopies. Agricultural and Forest Meteorology, 151, $1632-1640$.

THOMASSEN, E. W., S.; BOOSTEN, M.; DELFORTERIE, W.; NYSSEN, B. 2020. Revitalisering Nederlandse bossen. Bosgroepen.

WEEMSTRA, M., EILMANN, B., SASS-KLAASSEN, U. \& STERCK, F. J. 2013. Summer droughts limit tree growth across 10 temperate species on a productive forest site. Forest Ecology and Management, $306,142-149$.

WHITTET, R., LOPEZ, G. \& ROSIQUE-ESPLUGAS, C. 2021. Mid-rotation variation in growth, form and phenology of sycamore (Acer pseudoplatanus L.) provenances in field trials in England. Forestry: An International Journal of Forest Research. 


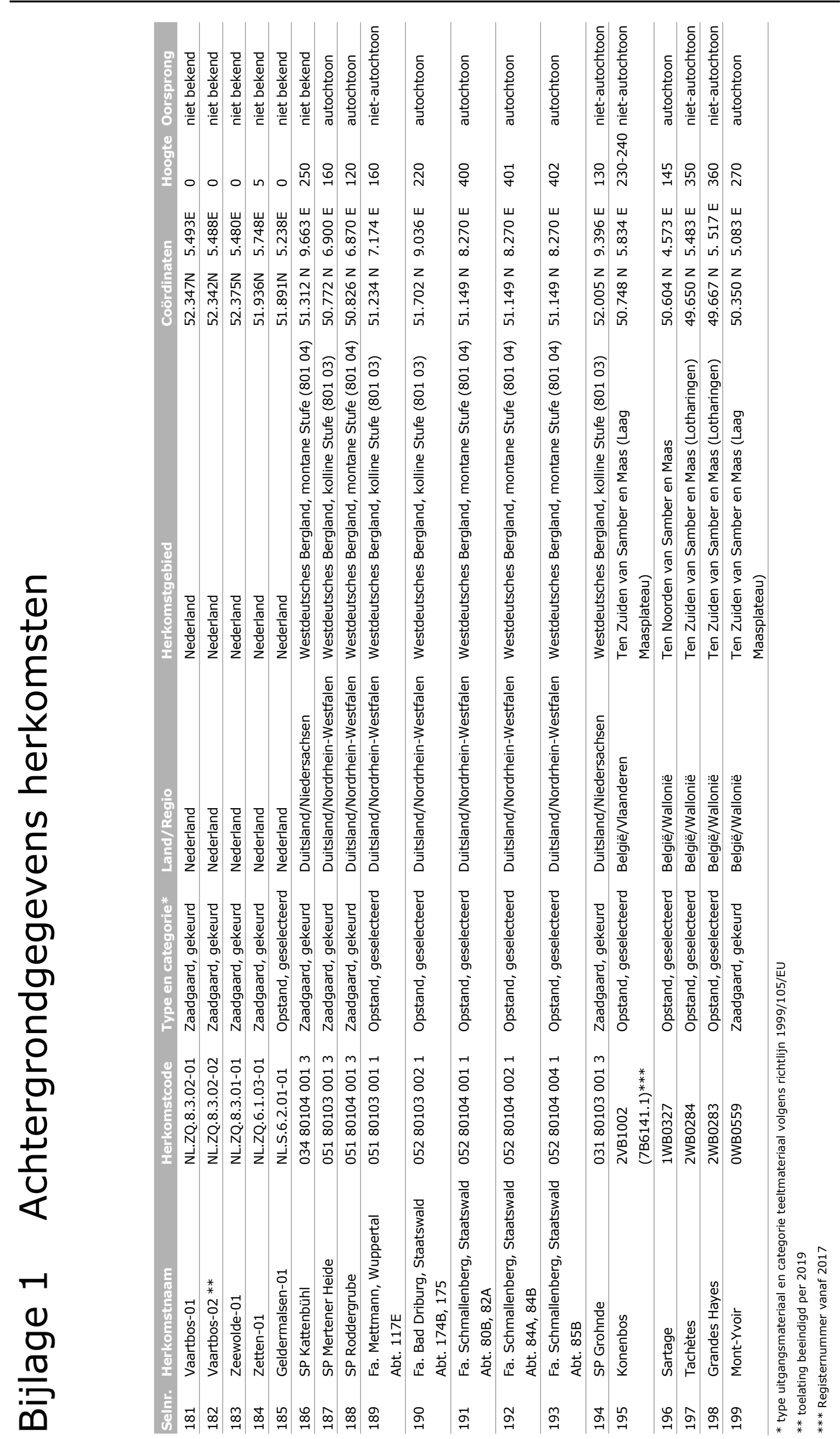




\section{Bijlage 2 Herkomstgebieden Duitsland en België}

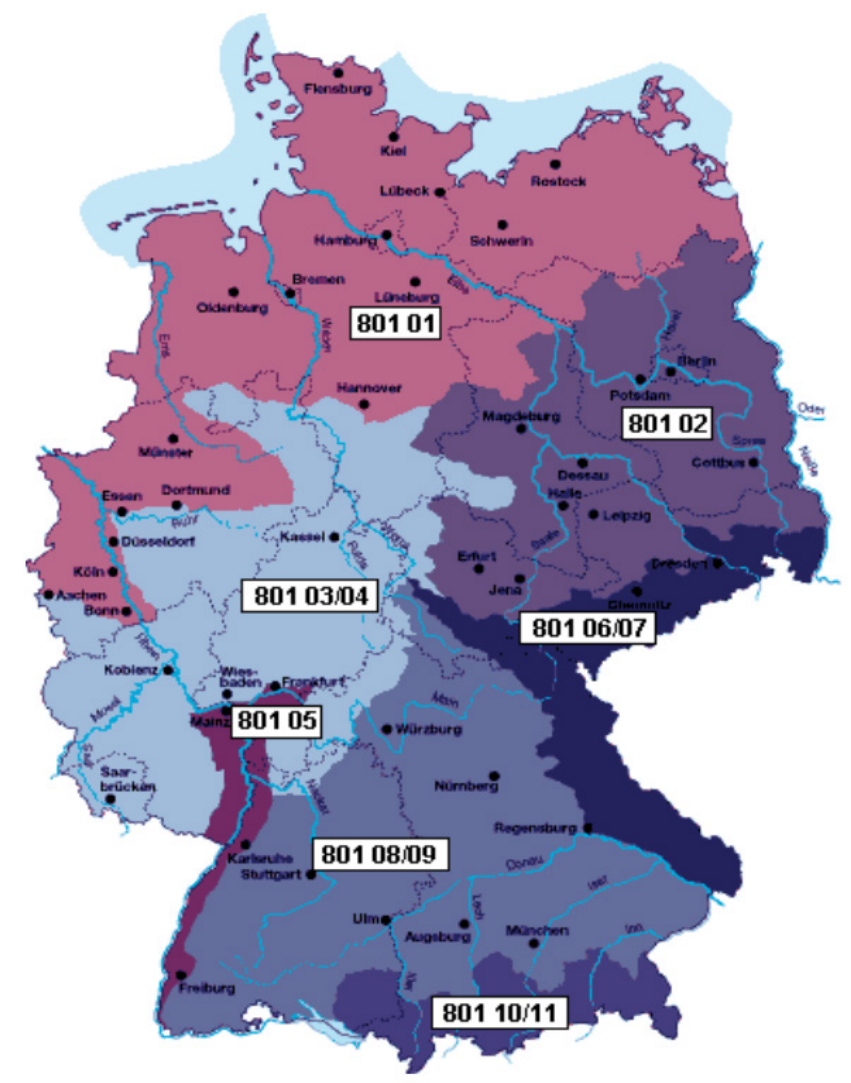

Herkomstgebieden in Duitsland voor gewone esdoorn (Krabel and Wolf, 2013).

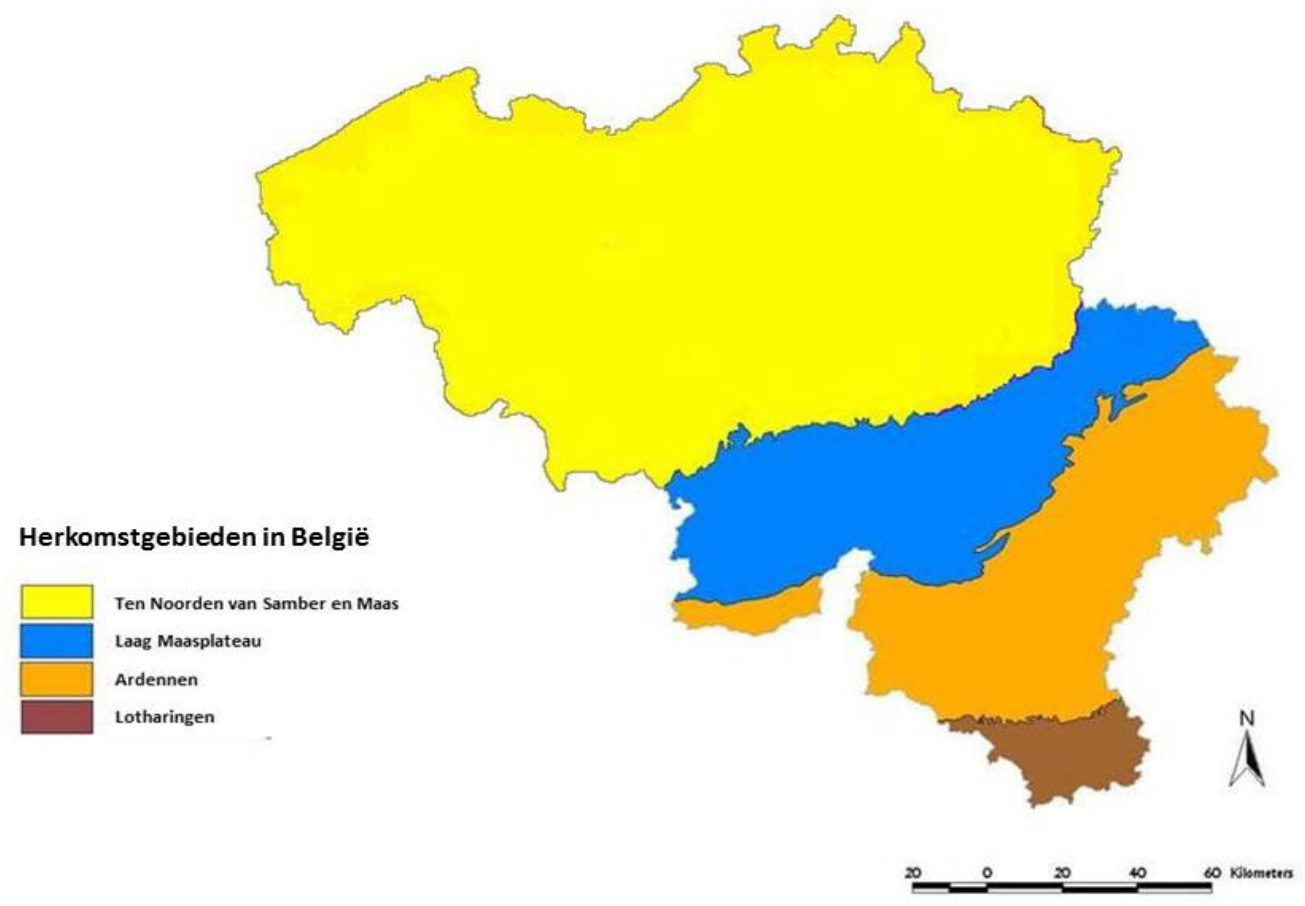

Herkomstgebieden in België (INBO, 2020). 


\section{Bijlage 3 INS-CGN-FG-079 Protocol uitloopstadia Acer soorten}

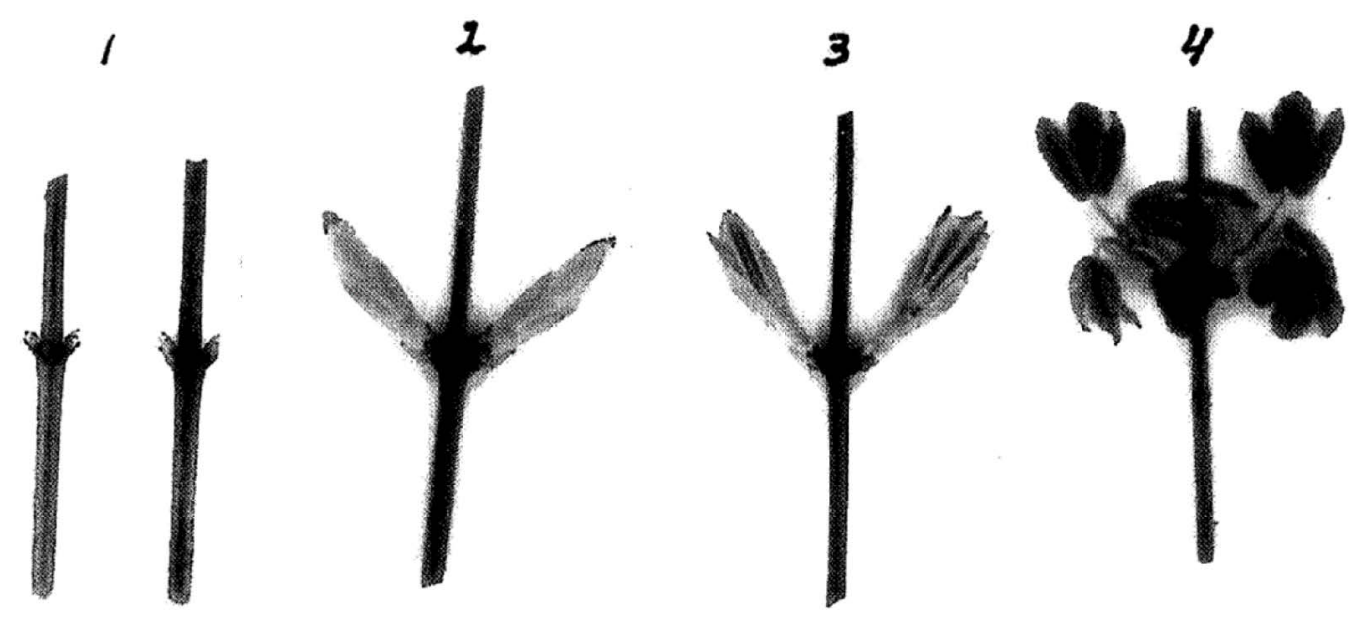

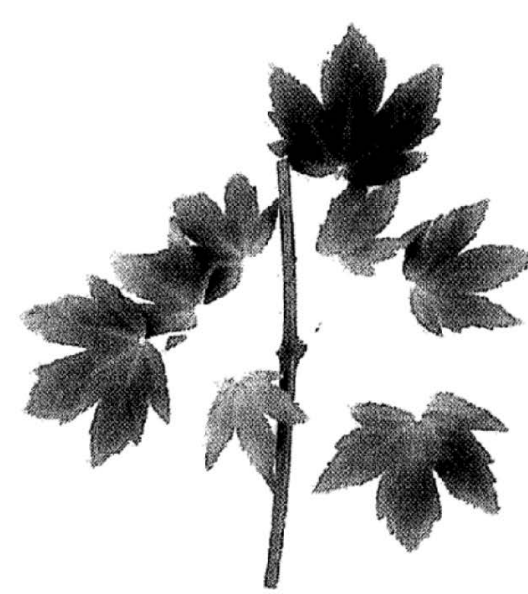

5

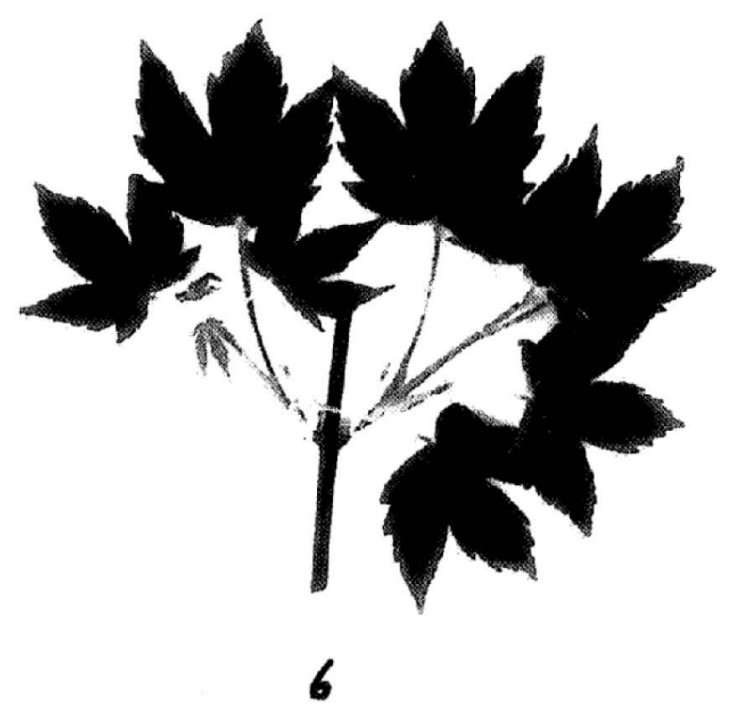




\section{Bijlage 4 Protocol rechtheid}

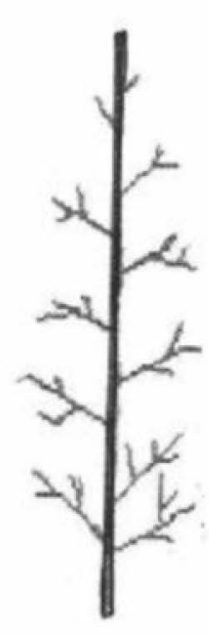

5

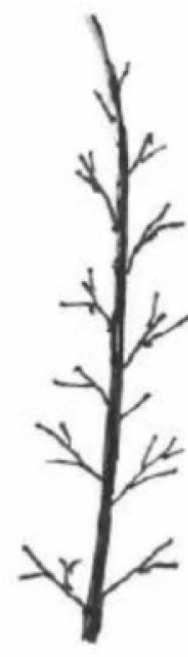

4

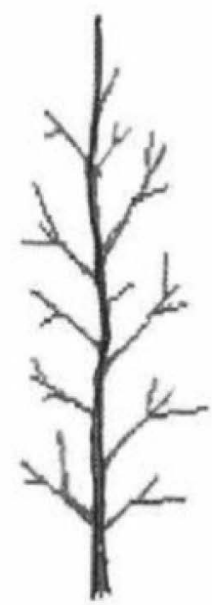

3

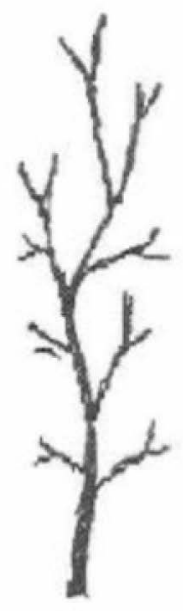

2

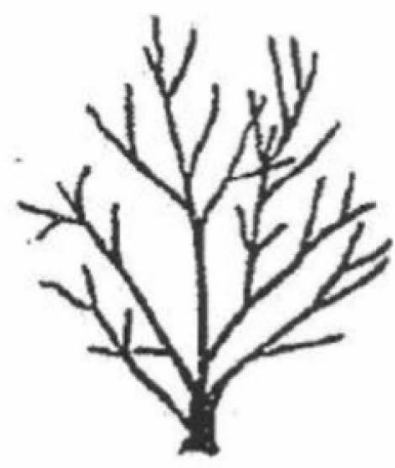

1

\begin{tabular}{ll} 
Scale values & Description \\
\hline 5 & absolutely straight stem \\
\hline 4 & fairly straight (in one direction slightly crooked) \\
\hline 3 & slight to moderate bends in different directions \\
\hline 2 & moderate to strong bends \\
\hline 1 & no straight stem \\
\hline
\end{tabular}




\section{Bijlage 5 Protocol vorken}

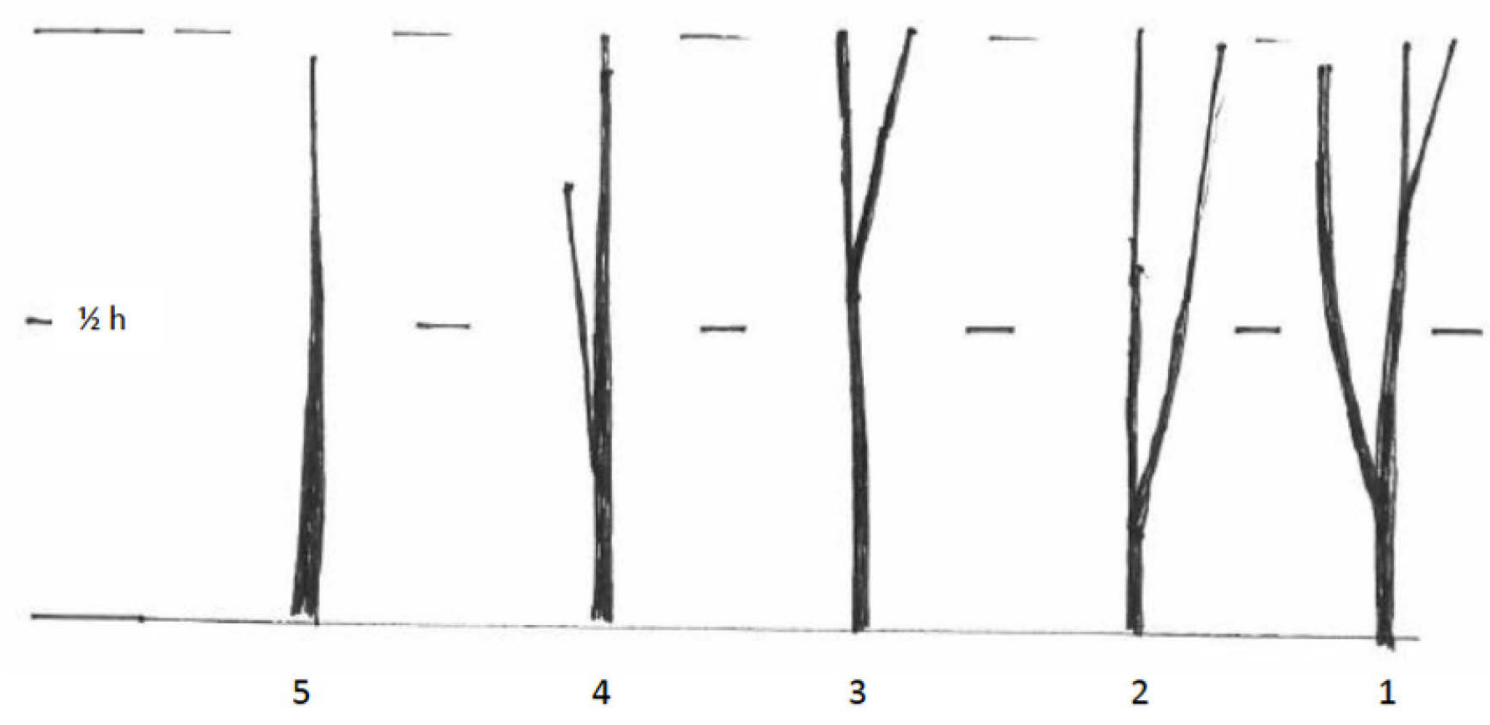

\begin{tabular}{ll} 
Scale values & Description \\
\hline 5 & no fork \\
\hline 4 & branch (ramicorn; thinner than a fork) with a similar angle \\
\hline 2 & fork(s) only in upper half of the tree height \\
\hline 1 & fork(s) only in the lower half of the tree height \\
\hline
\end{tabular}




\section{Bijlage 6 Bladuitloop 2011 \& 2012}
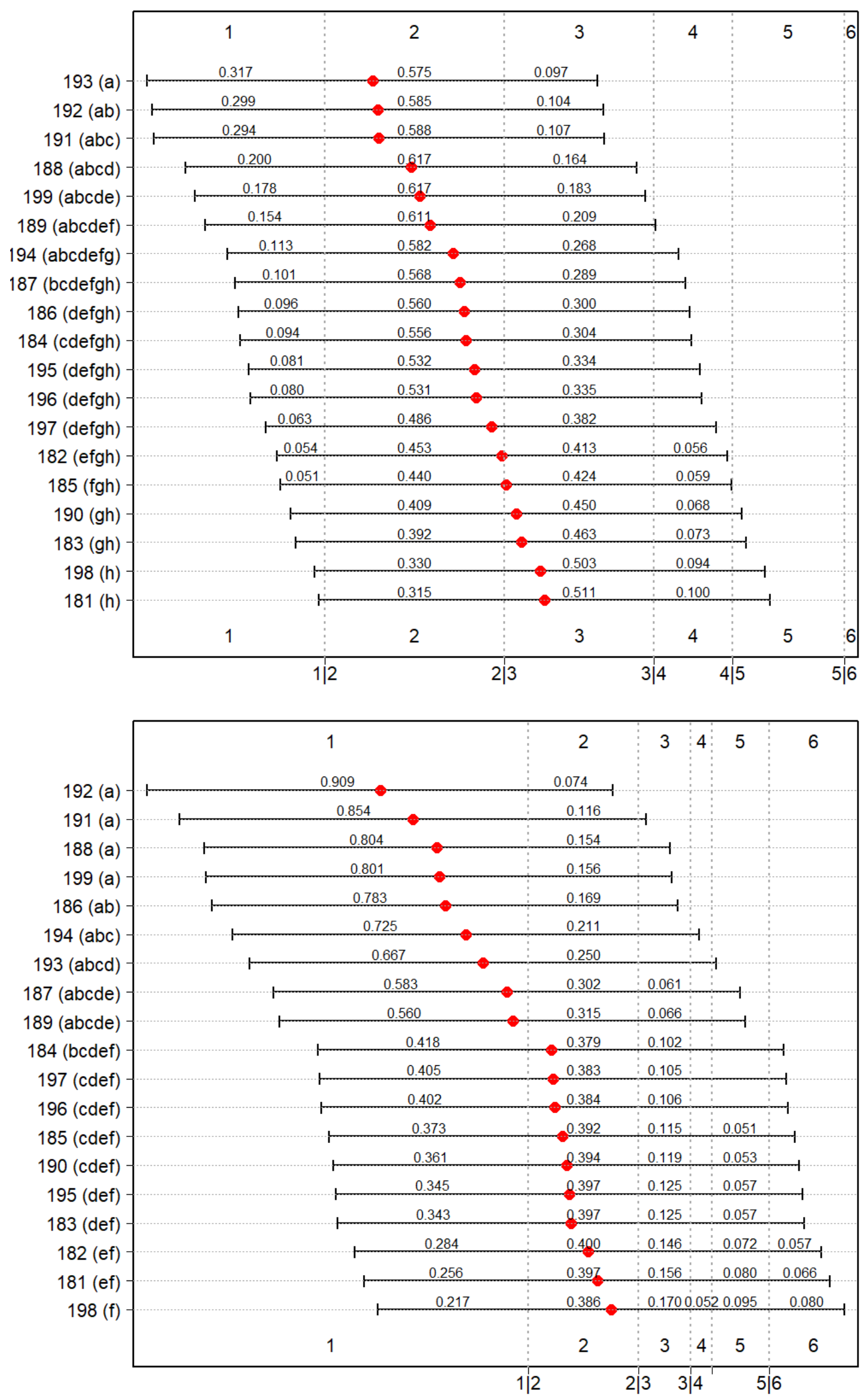


\section{Bijlage 7 Diameter en Hoogte 20 beste bomen per herkomst}

Gemiddelde diameter en hoogte van de 20 beste bomen per herkomst met betrouwbaarheidsintervallen.

\begin{tabular}{lllrl}
\hline Selnr. & Land van & Herkomstnaam & Top20 Diameter & Top 20 hoogte \\
181 & NL & Vaartbos-01 & & \\
\hline 182 & NL & Vaartbos-02 & $12,7(11,6-13,7)$ & $16,0(15,4-16,7)$ \\
\hline 183 & NL & Zeewolde-01 & $12,5(11,4-13,6)$ & $16,2(15,5-16,9)$ \\
\hline 184 & NL & Zetten-01 & $13,3(12,3-14,4)$ & $17,4(16,7-18,1)$ \\
\hline 185 & NL & Geldermalsen-01 & $10,5(9,4-11,6)$ & $14,9(14,3-15,6)$ \\
\hline 186 & D & SP Kattenbühl & $12,3(11,3-13,4)$ & $16,2(15,6-16,9)$ \\
\hline 187 & D & SP Mertener Heide & $10,8(9,7-11,9)$ & $14,9(14,2-15,5)$ \\
\hline 188 & D & SP Roddergrube & $12,5(11,4-13,6)$ & $16,7(16,1-17,4)$ \\
\hline 189 & D & Fa. Mettmann & $11,7(10,7-12,8)$ & $16,0(15,3-16,7)$ \\
\hline 190 & D & Fa. Bad Driburg & $11,6(10,5-12,7)$ & $15,8(15,1-16,5)$ \\
\hline 191 & D & Fa. Schmallenberg, Staatswald Abt. 80B, 82A & $10,5(9,5-11,6)$ & $15,1(14,5-15,8)$ \\
\hline 192 & D & Fa. Schmallenberg, Staatswald Abt. 84A, 84B & $9,0(7,9-10,1)$ & $14,2(13,5-14,8)$ \\
\hline 193 & D & Fa. Schmallenberg, Staatswald Abt. 85B & $7,9(6,7-9,0)$ & $13,5(12,8-14,2)$ \\
\hline 194 & D & SP Grohnde & $9,0(7,9-10,1)$ & $13,6(12,9-14,3)$ \\
\hline 195 & B & Konenbos & $11,5(10,4-12,5)$ & $16,5(15,9-17,2)$ \\
\hline 196 & B & Sartage & $11,7(10,6-12,7)$ & $15,2(14,5-15,9)$ \\
\hline 197 & B & Tachètes & $11,6(10,5-12,6)$ & $15,4(14,7-16,0)$ \\
\hline 198 & B & Grandes Hayes & $13,8(12,7-14,8)$ & $16,7(16,0-17,3)$ \\
\hline 199 & B & Mont-Yvoir & $14,4(13,4-15,5)$ & $17,0(16,4-17,7)$ \\
\hline & & Gemiddelde & $13,6(12,5-14,7)$ & $16,9(16,3-17,6)$ \\
\hline & & & 11,7 & 15,7 \\
\hline
\end{tabular}


CGN

Postbus 16

6700 AA Wageningen

cgn@wur.nl

www.wur.nl/cgn

Wageningen University \& Research CGN rapport 52
De missie van Wageningen University \& Research is 'To explore the potential of nature to improve the quality of life'. Binnen Wageningen University \& Research bundelen Wageningen University en gespecialiseerde onderzoeksinstituten van Stichting Wageningen Research hun krachten om bij te dragen aan de oplossing van belangrijke vragen in het domein van gezonde voeding en leefomgeving. Met ongeveer 30 vestigingen, 6.800 medewerkers ( $6.000 \mathrm{fte}$ ) en 12.900 studenten behoort Wageningen University \& Research wereldwijd tot de aansprekende kennisinstellingen binnen haar domein. De integrale benadering van de vraagstukken en de samenwerking tussen verschillende disciplines vormen het hart van de unieke Wageningen aanpak. 



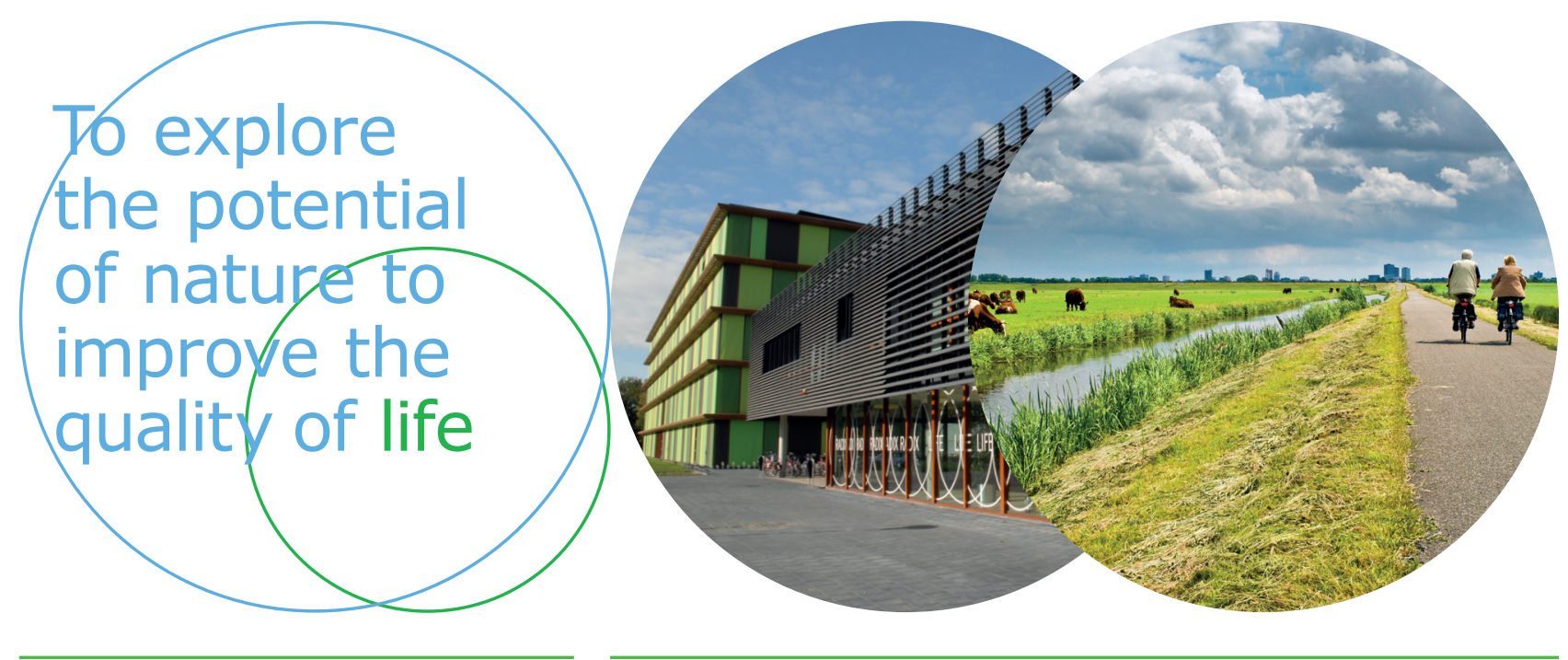

CGN

Postbus 16

6700 AA Wageningen

cgn@wur.nl

www.wur.nl/cgn

Wageningen University \& Research CGN rapport 52
De missie van Wageningen University \& Research is 'To explore the potential of nature to improve the quality of life'. Binnen Wageningen University \& Research bundelen Wageningen University en gespecialiseerde onderzoeksinstituten van Stichting Wageningen Research hun krachten om bij te dragen aan de oplossing van belangrijke vragen in het domein van gezonde voeding en leefomgeving. Met ongeveer 30 vestigingen, 6.800 medewerkers ( $6.000 \mathrm{fte}$ ) en 12.900 studenten behoort Wageningen University \& Research wereldwijd tot de aansprekende kennisinstellingen binnen haar domein. De integrale benadering van de vraagstukken en de samenwerking tussen verschillende disciplines vormen het hart van de unieke Wageningen aanpak. 